\title{
Opacity, transparency, and morphological priming: A study of prefixed verbs in Dutch
}

\author{
Ava Creemers*, Amy Goodwin Davies, Robert J. Wilder, Meredith Tamminga, David Embick \\ Department of Linguistics, University of Pennsylvania, 3401-C Walnut Street, Philadelphia, PA 19104-6228, USA
}

\section{A R T I C L E I N F O}

\section{Keywords:}

Morphological priming

Semantic opacity

Dutch prefixed verbs

Decomposition effects

Auditory word recognition

\begin{abstract}
A B S T R A C T
A basic question for the study of the mental lexicon is whether there are morphological representations and processes that are independent of phonology and semantics. According to a prominent tradition, morphological relatedness requires semantic transparency: semantically transparent words are related in meaning to their stems, while semantically opaque words are not. This study examines the question of morphological relatedness using intra-modal auditory priming by Dutch prefixed verbs. The key conditions involve semantically transparent prefixed primes (e.g., aanbieden 'offer', with the stem bieden, also 'offer') and opaque primes (e.g., verbieden 'forbid'). Results show robust facilitation for both transparent and opaque pairs; phonological (Experiment 1) and semantic (Experiment 2) controls rule out the possibility that these other types of relatedness are responsible for the observed priming effects. The finding of facilitation with opaque primes suggests that morphological processing is independent of semantic and phonological representations. Accordingly, the results are incompatible with theories that make semantic overlap a necessary condition for relatedness, and favor theories in which words may be related in ways that do not require shared meaning. The general discussion considers several specific proposals along these lines, and compares and contrasts questions about morphological relatedness of the type found here with the different but related question of whether there is morphological decomposition of complex forms or not.
\end{abstract}

\section{Introduction}

Theories of the mental lexicon differ substantially with respect to the role that specifically morphological representations and processing play in the comprehension and production of words. Much work in this area is framed as opposing theories that have morphological processing/representations and those that do not, often in ways that relate to the further question of whether or not there is morphological decomposition. The present paper addresses a distinct but related question concerning what types of factors are involved in morphological relatedness. In its simplest form, this is the question of whether words are related to one another in ways that are independent of semantics and phonology. Here, we will ask whether meaning overlap between words is a precondition for their relatedness, or whether words may be morphologically related despite not sharing a meaning.

A prominent tradition in theories of the mental lexicon makes regularity a precondition for relatedness. According to such theories, irregular words that appear to be morphologically complex are memorized in their full form in the mental lexicon, and, as such, have separate lexical entries from their putative stems. Irregularity, here, should be understood as irregular morpho-phonological forms (such as irregular allomorphy) and non-predictable meanings (semantic non-compositionality and opacity). In this type of model, for example, the compound teacup, which has a predictable or transparent meaning, is related to both tea and cup. The irregular bellhop, on the other hand, is not related semantically to either bell or hop; it is thus opaque. Theories that predict relatedness only for semantically transparent and phonologically regular forms have been proposed in very different looking architectures. For example, there are connectionist models which argue that morphological effects should be reduced to shared or interacting semantics and phonology (e.g., Gonnerman, Seidenberg, \& Andersen, 2007; Seidenberg \& Gonnerman, 2000); supralexical models which argue that morphemes may be accessed only after whole-word access (e.g., Diependaele, Sandra, \& Grainger, 2005; Giraudo \& Grainger, 2001, 2003); and (parallel) Dual-Route models, which assume that both fullform based processing and decompositional processing are available routes, with (ir)regularity determining which path is taken (e.g., Baayen, Dijkstra, \& Schreuder, 1997; Bertram, Laine, Baayen, Schreuder, \& Hyönä, 2000; Burani \& Caramazza, 1987; Burani \& Laudanna, 1992; Caramazza, Laudanna, \& Romani, 1988; Frauenfelder

\footnotetext{
* Corresponding author.

E-mail address: creemers@sas.upenn.edu (A. Creemers).
} 
\& Schreuder, 1992; Schreuder \& Baayen, 1995).

While the views summarized above differ on some points, they share the crucial claim that the relation between an opaque word and its apparent stem is different from the relation between a transparent word and its stem. These views contrast with approaches that do not make morphological relatedness effects contingent upon semantic transparency. In fully decompositional models, for example, bellhop is related to both bell and hop because it consists of these two parts, in spite of semantic opacity (Smolka, Preller, \& Eulitz, 2014; Smolka, Libben, \& Dressler, 2019; Stockall \& Marantz, 2006; Taft, 1979, 2004; Taft \& Forster, 1975; cp. Marantz, 2013; Embick, 2015). Such models predict these relatedness effects because they are centered on the idea that morphological complexity implies independent morphological processing and representation- that is, morphological relatedness can exist without semantic overlap. Importantly, though, similar relatedness effects might also be captured in learning models (Baayen, Milin, Đurđević, Hendrix, \& Marelli, 2011; Baayen, Chuang, Shafaei-Bajestan, \& Blevins, 2019; Milin, Feldman, Ramscar, Hendrix, \& Baayen, 2017) that begin with very different architectural assumptions than decompositional models. We return to this point in our general discussion.

The present study probes the question of morphological relatedness with the use of prefixed verbs in Dutch. Semantically speaking, prefixed verbs produce meanings that may be transparent or opaque. To illustrate, a Dutch verb like bieden ('offer') may combine with the particle aan to form the transparently related aanbieden ('offer'), and with the prefix ver- (which has no straightforward meaning, although there are some sub-patterns in its use; see Lieber \& Baayen, 1993) to form verbieden ('forbid'). This verb is semantically opaque in the sense that its meaning cannot be predicted from the meaning of its parts. The words bieden and verbieden are morphologically related: for instance, they both share the same unpredictable allomorphy in the past tense and participle forms. However, and given their lack of semantic overlap, a diagnostic beyond shared allomorphy is required in order to draw any strong conclusions about their relatedness, since their formal identity could be a historical accident.

A potential diagnostic for morphological relatedness is provided by morphological priming. For example, if a prime teacher produces significant facilitation for a target teach, this is often taken as evidence for morphological relatedness between the two words: informally, they both involve the word teach. Of course, any interpretation of this type must take into account the fact that teacher and teach are also semantically and phonologically (or orthographically) related, such that putative effects of morphological relatedness could be attributed to these other types of representations, not morphological processing or decomposition per se. It is in the light of this observation that the significance of opaque forms can be seen clearly. With an opaque prefixed verb like Dutch verbieden ('forbid'), semantic relatedness is not an issue for interpreting findings since, crucially, the meaning of the complex form shows no or only very little overlap with that of its stem. To the extent that formal (phonological or orthographic) relatedness can be eliminated from consideration through the use of controls, opaque primes offer a window into specifically morphological representations and processing.

We report the results from two intra-modal auditory priming experiments examining Dutch prefixed verbs. Morphological priming is investigated by manipulating the semantic and phonological relatedness of prime-target pairs. The crucial question addressed is whether or not there are morphological representations and processes that are independent of phonology and semantics. Specifically, we test whether semantic overlap forms a necessary condition for morphological relatedness between words, or whether morphological priming effects can be obtained in the absence of semantic compositionality, e.g., whether a complex verb like verbieden ('forbid') primes its stem bieden ('offer').

\subsection{Prior work on 'semantically opaque' affixed forms}

An important background to the present paper is the observation that the experimental literature on opaque forms shows contradictory findings for even closely related languages. For instance, morphological processing is said to be influenced by semantic transparency in English and French (Feldman, Soltano, Pastizzo, \& Francis, 2004; Gonnerman et al., 2007; Longtin, Segui, \& Halle, 2003; Marslen-Wilson, Tyler, Waksler, \& Older, 1994; Rastle, Davis, Marslen-Wilson, \& Tyler, 2000), but not in German (Smolka, Komlosi, \& Rösler, 2009; Smolka et al., 2014; Smolka, Gondan, \& Rösler, 2015; Smolka et al., 2019) and various Semitic languages (Boudelaa \& Marslen-Wilson, 2004; Boudelaa \& Marslen-Wilson, 2015; Feldman \& Bentin, 1994; Frost, Forster, \& Deutsch, 1997; Ussishkin, Dawson, Wedel, \& Schluter, 2015).

A related complexity, one that might, in part, be responsible for the inconsistent cross-linguistic findings, is that prior investigations have been motivated by at least two distinct types of questions, and have employed different types of stimuli accordingly. The first research direction is one that focuses on orthography-based decomposition of pseudo-derived forms such as corner, which shows only an apparent morphological relation to corn. The second research direction looks at semantically opaque forms that might be decomposed on the basis of true morphological structure. A careful distinction between these types of questions, and the stimuli used in the different types of studies, is essential to understanding which words might or might not be related in the mental lexicon.

\subsubsection{Pseudo-derived forms}

A first line of research investigates the processing of pseudo-derived words like corner. While it is standardly assumed in the literature that this word is not a morphological derivative of corn, it can nevertheless be parsed into corn and er, a string that is orthographically identical to an independently occurring affix in the language (-er). Stimuli of the pseudo-derived type have been used in a wide range of masked priming studies, in which the prime is unavailable for conscious report due to short prime exposure. Early studies have argued in favor of a semantically blind mechanism of pre-lexical morpho-orthographic decomposition (Beyersmann et al., 2016; Diependaele, Sandra, \& Grainger, 2009; Diependaele et al., 2005; Longtin et al., 2003; MarslenWilson, Bozic, \& Randall, 2008; McCormick, Rastle, \& Davis, 2008; Rastle et al., 2000; Rastle \& Davis, 2003; Rastle, Davis, \& New, 2004, i.a.), as both farmer $\rightarrow$ FARM and corner $\rightarrow$ CORN led to significant priming effects. At the same time, no such effects were found for brothel $\rightarrow$ BROTH, where, crucially, the string el does not form a potential suffix.

A different line of work, with different experimental designs and statistical analyses, has challenged these form-then-meaning accounts. Responses to semantically transparent pairs were shown to be significantly faster than responses to pseudo-related pairs in Feldman, O'Connor, and del Prado Martín (2009) and Feldman et al. (2015) (see also Andrews \& Lo, 2013), and in addition, effects for pseudo-related pairs (corner $\rightarrow C O R N$ ) were reported to be equal to orthographically related pairs (cornea $\rightarrow$ CORN ) in Milin et al., 2017. Moreover, it has been shown that semantic effects emerge early in the word recognition of transparent derived and pseudo-derived forms (Schmidtke, Matsuki, \& Kuperman, 2017). These results are compatible with a form-andmeaning account, in which word recognition involves the simultaneous access of morphological and semantic information. However, the sequential form-then-meaning position has been defended in important neuro-imaging work (Lavric, Rastle, \& Clapp, 2011; Lavric, Elchlepp, \& Rastle, 2012; Whiting, Shtyrov, \& Marslen-Wilson, 2014), which offers a time-sensitive method that allows investigation of the specific temporal ordering of different types of analysis during visual word 
recognition. The matter thus remains somewhat open, and will not be our central concern here.

\subsubsection{Opaque forms}

In this paper, our focus is not on pseudo-derived words, but instead on words that are morphologically derived, but have no semantic relation to their stem. We refer to these as opaque (see Feldman et al., 2015 , p. 2; footnote 1). As a working definition, word $W_{2}$ is opaque with respect to word $W_{1}$ when $W_{2}$ consists of $W_{1}$, plus an element that is an affix in the language, and when there is at least some evidence for these words being related. Different factors can be considered in assessing evidence for a possible morphological relation. A shared pattern of idiosyncratic morphophonology in the form of allomorphy might play this role. For example, it might be hypothesized that the verbs understand and withstand share the stem stand that also occurs by itself as a verb, since all three verbs have the same, idiosyncratic past tense form stood (cf. Aronoff, 1976). Crucially, no evidence for morphological relatedness exists for pseudo-derived words.

For the reasons outlined earlier, the point of looking at opaque stimuli is that there is no evidence from meaning for relatedness. The behavior of opaque and transparent forms have typically been investigated in overt priming studies (as opposed to masked), in which primes are consciously perceived under visual priming at a long Stimulus Onset Asynchrony (henceforth SOA), or with auditory primes. Studies of this sort have led to different conclusions.

For English and French, it has been argued that only semantically transparent primes facilitate target processing in overt priming experiments. In English, morphologically and semantically related primetarget pairs (departure $\rightarrow$ depart) show significant effects regardless of the SOA used (43, 72, and $230 \mathrm{~ms}$ ), while morphologically related but semantically unrelated pairs (apartment $\rightarrow$ apart) show priming only at the shortest SOA (Rastle et al., 2000). Also, in cross-modal priming experiments in English and French, priming is obtained for semantically transparent pairs, but not (or to a significantly smaller extent) for semantically opaque pairs (Feldman et al., 2004; Gonnerman et al., 2007; Longtin et al., 2003; Marslen-Wilson et al., 1994). Similar effects have been shown for Serbian (Feldman, Barac-Cikoja, \& Kostić, 2002).

The results for English and French contrast starkly with findings for Semitic languages with non-concatenative morphology, such as Arabic (Boudelaa \& Marslen-Wilson, 2004, 2005, 2015), Hebrew (Feldman \& Bentin, 1994; Frost et al., 1997, but see Frost, Deutsch, Gilboa, Tannenbaum, \& Marslen-Wilson (2000) who find a significant difference between opaque and transparent conditions), and Maltese (Ussishkin et al., 2015). In these languages, robust morphological priming effects are obtained in the absence of semantic transparency. In Arabic cross-modal priming, for example, prime-target pairs of deverbal nouns sharing a root morpheme $(\{\mathrm{dxl}\})$ which are semantically transparent ([madxalun] 'inlet' $\rightarrow$ [duxuulun] 'entry') show a priming effect of equal magnitude as semantically opaque pairs ([mudaaxalatun] 'conference' $\rightarrow$ [duxuulun] 'entry') (Boudelaa \& Marslen-Wilson, 2015).

Importantly, recent studies on German prefixed verbs (Smolka et al., $2009,2014,2015,2019)$ show that this pattern of results is not restricted to languages with non-concatenative morphology. In a series of overt visual and cross-modal priming experiments (Smolka et al., 2014), both semantically transparent (zubinden 'tie' $\rightarrow$ binden 'bind') and semantically opaque (entbinden 'deliver' $\rightarrow$ binden 'bind') derivations significantly facilitate responses relative to the unrelated condition, while neither semantically related synonyms (zuschnüren 'tie' $\rightarrow$ binden 'bind') nor form-related pairs (abbilden 'depict' $\rightarrow$ binden 'bind') differ from the unrelated condition.

On the face of it, the study of opaque words has produced a contradictory set of findings. However, some additional factors must be considered in assessing the apparent cross-linguistic differences. This is particularly the case with the languages argued to show facilitation for transparent but not opaque primes, such as English and French.

For English, matters of morphological relatedness may be obscured by complexities of the language that are the result of its history. Specifically, a large part of the vocabulary of English is borrowed from different Latinate languages. The Latinate part of English contains many words that look like they might be morphologically related (and which are often related etymologically), and many of the commonly used words in English priming studies are from the Latinate part (e.g., successor, casualty, designate; used in Feldman et al., 2004; Marslen-Wilson et al., 1994; Rastle et al., 2000). However, the synchronic status of many of these words in the minds of speakers is unclear. It is plausible that the Latinate part of the vocabulary is represented and accessed in a way that is qualitatively distinct from the Germanic vocabulary. For instance, studies of the development of knowledge of English derivational morphology show that much of it is acquired quite late, continuing to improve throughout adolescence and into adulthood, and that mastery of derivational morphology involves a longer, more open ended course compared to inflectional morphology (Anglin, 1993; Derwing \& Baker, 1986; Duncan, Casalis, \& Colé, 2009; Mahony, Singson, \& Mann, 2000, Singson et al., 2000, i.a.). It is, hence, possible that some of the words classified as opaque in previous studies on English are actually better considered as pseudo-derived, with consequences for morphological priming.

For French, it is not clear that the stimuli have been classified in ways that correctly reflect the pseudo-derived versus opaque distinction. The Longtin et al. (2003, Experiment 2) study, for example, includes 'opaquely affixed' (rater 'to miss' $\rightarrow$ rat 'rat') and 'pseudo-affixed' forms (traiter 'to treat' $\rightarrow$ trait 'feature'), but uses these terms in a different way than we do. For Longtin et al. (2003), the distinction is meant to reflect the idea that 'pseudo-affixed' forms are connected neither semantically nor etymologically, while 'opaquely affixed' forms share an etymological connection, but are no longer related semantically. However, there is no reason to believe that this distinction is real for speakers of French, as it is unlikely that the etymological status of the 'opaque' words has psychological relevance and is part of what is represented in an individual's mental lexicon. Since there is no evidence for synchronic morphological relatedness between primes and targets in either of these conditions, it seems likely that both types of words are pseudo-derived. The absence of cross-modal priming in the opaque condition is, therefore, unsurprising.

We take away two main points from this prior work: first, the need to be clear about the pseudo-derived versus opaque distinction; and second, the fact that there is a need for more systematic investigation of opaque affixation in additional languages.

\subsection{Dutch complex verbs}

Our study of Dutch prefixed verbs looks directly at the effects of semantic transparency and opacity on morphological relatedness. Similar to German complex verbs (Smolka et al., 2009, 2014, 2015, 2019), Dutch complex verbs are prefixed with a separable or inseparable prefix, ${ }^{1}$ and are productive and frequently used. In contrast to pseudo-derived words like corner, Dutch prefixed verbs are true morphological derivatives of their stems. Synchronic evidence for their morphological relatedness comes from the fact that complex verbs and their stems share irregular allomorphy. Many of the stems of prefixed verbs show unpredictable allomorphy in their preterite and past participle forms, a manifestation of the strong/weak verb distinction that is a property of Germanic languages. Crucially, prefixed verbs show the

\footnotetext{
${ }^{1}$ It is common to refer to separable prefixes as 'particles'. However, some of the affixes that are typically referred to as particles, like aan, may in fact occur as inseparable prefixes. An example of this is the prefixed verb aanschouwen ('see'), for which the prefix and verb are inseparable in main clauses, even though aan is not one of the common prefixes be-, ver-, or ont-. Therefore, in this paper, we use the terms separable versus inseparable prefixed verbs, rather than particle and prefix verbs.
} 
same patterns of allomorphy as their stems, independent of semantic transparency or opacity (e.g., bieden 'offer' boden 'offered'; aanbieden 'offer' aanboden 'offered'; verbieden 'forbid' verboden 'forbade'). Many prefixed verbs (that is, the irregular ones) thus provide morphophonological evidence for language learners that they are related to their unprefixed stems.

Dutch complex verbs provide an ideal test case to see whether morphological priming occurs in the absence of semantic compositionality, as these verbs may differ in meaning relatedness between the stem and the complex verb from fully transparent to fully opaque. For instance, optrekken ('pull up'), uittrekken ('remove, take off'), and vertrekken ('leave') all take trekken ('pull') as their stem but differ from fully transparent to fully opaque.

Morphosyntactially speaking, the prefixes are of two types: separable ones, which appear in a different position from the verb in 'verb second' clauses, and inseparable ones, which always appear prefixed to the verb stem. Importantly, it is not the case that there is a one-to-one relation between (in)separability of the prefix and semantic transparency/opacity of the complex verb, as inseparable and separable prefixes are both associated with transparent and opaque meanings. For instance, while the inseparable prefix ver- with bieden ('offer') results in a semantically opaque complex verb verbieden ('forbid'), the same inseparable prefix with krijgen ('get') results in a semantically transparent complex verb verkrijgen ('get, obtain'). Similarly, while aanbieden ('offer') with the separable prefix aan is semantically transparent, the same prefix with breken ('break') results in the semantically opaque verb aanbreken ('open, begin').

Related to the cross-linguistic differences discussed above, a study by Zwitserlood, Bolwiender, and Drews (2005, Experiment 2) is often referred to as showing that Dutch behaves like French and English in the sense that morphological priming is dependent on semantic overlap (see e.g., Amenta \& Crepaldi, 2012; Hall et al., 2016; Smolka et al., 2014). A closer look at this study, however, shows that this particular conclusion is not warranted. The experiment in question uses sentence primes to activate the conceptual representation of (the stem of) the complex verb, and therefore investigates semantic rather than morphological priming of prefixed verbs. The question posed is whether a sentence like hij slingerde haar de meest gemene dingen naar het hoofd ('he shouted all sorts of mean things when talking to her') activates the conceptual representation of the complex verb uitschelden ('verbally abuse'), which does not occur in that sentence. This type of experiment is not intended to probe morphological processing and representation per se; instead, it is directed at concepts, associated either with an entire sentence, or with a prefixed verb. The results in Zwitserlood et al. (2005) indicate that there might be a difference between transparent and opaque prefixed verbs, but this difference relates to the activation of conceptual representations, not to morphological representations.

A study by Schreuder, Burani, and Baayen (2003) does look at morphological effects for opaque words in Dutch, and suggests that at least in Dutch low-frequency morphologically complex but semantically opaque words (such as branding 'surf, the rolling and splashing of the waves', which consists of two high-frequency constituents: brand 'fire, to burn' and the nominalizing suffix -ing), the component constituents are activated. However, a semantic priming experiment in the same paper also suggests that the first meaning to become available is the opaque (and appropriate) full-form meaning, and that the transparent reading (the meaning that is a possible reading morphologically, but that is not used in Dutch) emerges only later in time. Eye-tracking studies with Dutch compounds (Kuperman, Schreuder, Bertram, \& Baayen, 2009) and suffixed words (Kuperman, Bertram, \& Baayen, 2010) also suggest that whole-word effects are present from the earliest fixation onward, but that both full forms and constituent morphemes play a role in the processing of complex words.

Finally, a recent study by De Grauwe, Lemhöfer, \& Schriefers (2019) shows significant morphological priming effects for Dutch separable prefixed verbs that are semantically transparent (opschrijven 'write down' $\rightarrow$ schrijven 'write') and semantically opaque (toekennen 'award' $\rightarrow$ kennen 'know') in an overt visual priming paradigm. In addition to the effects of semantic transparency, this study also manipulates the motor-relatedness of the simple verb constituent (the degree to which a word refers to a movement performed with specific muscles), following a specific line of reasoning from fMRI studies. While morphological effects seem independent of semantic transparency in these experiments, a semantic stem priming experiment shows significant semantic priming effects only for transparent motor verbs (pen 'pen' $\rightarrow$ opschrijven 'write down'), but not for semantically opaque or non-motor-related words.

However, the experimental design in De Grauwe et al. (2019) does not incorporate phonological and semantic control conditions. Therefore, the results remain suggestive, as alternate explanations are available for the reasons discussed above. The design in the present study differs from De Grauwe et al. (2019) in some crucial ways. First, instead of using a between-items design in which targets differ across priming conditions, we use a within-items design. This allows us to compare response times to the same targets across conditions, as the same target is used with a different prime in each condition. Second, we include phonological and semantic conditions to investigate whether any obtained morphological effects are in fact due to form and/or meaning overlap.

Taken together, prior work provides some suggestions as to how the opaque/transparent distinction affects the representation of Dutch words, but does not establish definitive conclusions on this point. Therefore, in the present study, we further investigate the effect of semantic transparency on morphological processing in Dutch prefixed verbs.

\subsection{The present study}

While most previous studies have addressed the issue of morphological processing by investigating the visual identification of target words (in masked, overt, and cross-modal paradigms), we investigate auditory word recognition. Although less commonly used in priming paradigms, auditory presentation has been shown to successfully probe many aspects of lexical representation (Bacovcin, Goodwin Davies, Wilder, \& Embick, 2017; Balling \& Baayen, 2008; Goodwin Davies et al., submitted for publication; Kouider \& Dupoux, 2009, Wilder, Goodwin Davies, \& Embick, 2019, i.a.). Examining the effects of transparency/opacity in the auditory modality is important for multiple reasons.

First, and most basically, the auditory modality is viewed as the most natural one for spoken language. The acquisition of oral language precedes the acquisition of written language, and speaking and listening are seen as 'primary' linguistic activities that secondary activities such as reading and writing are parasitic upon (e.g., Mattingly, 1984).

Second, the two modalities have a very different temporal structure. Unlike visual word recognition, in auditory word recognition the acoustic signal unfolds over time, which has consequences for lexical access. For instance, the Cohort model (Marslen-Wilson, 1984) assumes that the unfolding phonological input progressively narrows down the set of possible candidates (the cohort), until a Uniqueness Point is reached at which a word's cohort is reduced to a single member. For morphologically complex words, a second critical point in auditory comprehension has been shown to exist: the Complex Uniqueness Point, which is the point at which the complex word deviates from its morphological competitors (Balling \& Baayen, 2008, 2012). Crucially, due to the incremental nature of the auditory word processing, the pieces that make up a multi-morphemic stimulus become available to the listener at different, specifiable times (Wurm, 2000), and the listener does not have access to the stem and affix of a complex word at the same time. In contrast, with visually presented words, the letters that make up the word are simultaneously presented, and eye-tracking studies show that many complex words are read with one fixation only 
(for an overview see Bertram, 2011), such that stems and affixes may be processed at the same time.

A third reason for examining auditory processing is that there is some evidence suggesting crucial differences in the effects that are detected in the different modalities. One case in point is the fact that masked priming effects for stimuli like corner $\rightarrow$ corn have been argued to be orthographically driven (Rastle et al., 2004; Rastle \& Davis, 2008). Another case is the comparison between repetition priming (e.g., frog $\rightarrow$ frog) and morphological priming (e.g., frogs $\rightarrow$ frog), for which some studies report identical facilitation (Forster, Davis, Schoknecht, \& Carter, 1987; Stanners, Neiser, Hernon, \& Hall, 1979), while others report greater facilitation for repetition priming than for (inflectional) morphological priming (Kouider \& Dupoux, 2009). As discussed in Wilder et al. (2019), the apparent contradiction might arise due to differences in modality: the studies reporting no difference between repetition and morphological priming employ visual stimuli, whereas those reporting a difference are auditory. The differences in question might very well be related to the contrasts between (near-) simultaneous and incremental arrival of the word mentioned above.

In the present study, we report on two experiments investigating Dutch prefixed verbs that are (i) morphologically and semantically related, (ii) morphologically related but semantically opaque, (iii) phonologically related, but semantically and morphologically unrelated, (iv) semantically related, but morphologically and phonologically unrelated, and (v) unrelated controls which function as our baseline. In Experiment 1, prime-target pairs are manipulated with respect to their morphological, semantic, and phonological relatedness in an immediate priming paradigm. In Experiment 2, we add a semantic condition, and manipulate the number of intervening items between prime and target. We use the experimental design used in Smolka et al. (2014), but due to the change in modality, we include a phonological condition rather than an orthographic condition, which serves to control for the potential effects of rhyme priming (see e.g., Norris, McQueen, \& Cutler, 2002). In addition, we make use of a continuous lexical decision task, rather than a paired presentation of primes and targets with responses only to the latter. This minimizes the difference between primes and targets and therefore makes pairings and thus conditions under investigation less apparent to participants.

\section{Experiment 1}

The aim of the first experiment is to investigate the role of morphological structure in the lexical representation of complex verbs in Dutch, while teasing apart semantic, phonological, and morphological effects. Our research question is as follows: does a morphologically complex verb in Dutch prime its stem, and if so, what is the contribution of semantic and phonological overlap to these priming effects? While any theory predicts priming effects for targets with primes that are both morphologically and semantically related, priming effects for primes that are morphologically but not semantically related to their target are expected only if morphological processing is independent of semantic and phonological overlap. Moreover, if morphological effects are different from mere phonological overlap, we expect to obtain priming effects in the morphologically related condition that are significantly larger in magnitude than the effects in the phonological condition.

\subsection{Method Experiment 1}

\subsubsection{Participants}

Participants were 32 adult native speakers of Dutch, most of whom were students or recent alumni of the University of Amsterdam (mean age $=27.75 ; \mathrm{sd}=8.42$ ). All participants were raised monolingual, and reported having no reading, hearing, or other language disorders. Some of the participants were recruited through www.proefbunny.nl, a website for participant recruitment. Participants were paid a small fee (5 euros) for their participation.
Table 1

Conditions and example critical items Experiment 1, for the target (the stem + infinitival suffix) and the primes in the Morphologically and Semantically related (MS), only Morphologically related (M), Phonologically related $(\mathrm{Ph})$, and Control $(\mathrm{C})$ conditions.

\begin{tabular}{|c|c|c|c|c|}
\hline Target & MS prime & M prime & $\mathrm{Ph}$ prime & C prime \\
\hline bieden & aanbieden & verbieden & bespieden & opjagen \\
\hline 'offer' & 'offer' & 'forbid' & 'spy' & 'hurry, rush' \\
\hline schieten & beschieten & opschieten & begieten & bezoeken \\
\hline 'shoot' & 'fire on/at' & 'hurry up' & 'pour over' & 'visit' \\
\hline werpen & afwerpen & ontwerpen & aanscherpen & uitdraaien \\
\hline 'throw' & 'throw off' & 'design' & 'sharpen' & 'print out' \\
\hline
\end{tabular}

\subsubsection{Materials and design}

The critical stimuli that form the targets in the first experiment are 36 base verbs that are high frequency simplex verbs. Each target was combined with four primes, resulting in 144 prime-target pairs. All primes were complex verbs, formed with a separable or inseparable prefix. We do not predict a difference in processing between the two types of prefixes (following Smolka et al., 2019, who show equally robust morphological processing for inseparable and separable prefixed verbs), but we include this information as a predictor in our model. Both types of prefixes occur in every prime condition. Prime-target relations are as follows: morphologically and semantically related (MS; e.g., aanbieden 'offer' $\rightarrow$ bieden 'offer'), morphologically related but semantically opaque (M; e.g., verbieden 'forbid' $\rightarrow$ bieden 'offer'), phonologically related ( $\mathrm{Ph}$; bespieden 'spy' $\rightarrow$ bieden 'offer'), and controls (C; e.g., opjagen 'hurry, rush' $\rightarrow$ bieden 'offer') which serve as the baseline and are unrelated in morphology, meaning, and phonology to their target. In the phonological condition, the stem of the prime and the target rhyme: they only differ in their onset consonant or consonant cluster, while sharing the rhyme. Table 1 presents examples of the stimuli used. The full stimulus list can be found in the appendix.

To establish the semantic relatedness between primes and targets, a semantic relatedness pre-test was conducted with at least two candidate complex verbs for every target base verb. The details of this pre-test can be found in the appendix. Frequencies for all primes and targets were extracted from the SUBTLEX-NL database (Keuleers, Brysbaert, \& New, 2010). Primes were matched for frequency as much as possible. Neighborhood densities for the targets are extracted from CLEARPOND-Dutch (PTAN values, Marian, Bartolotti, Chabal, \& Shook, 2012). Both frequencies and neighborhood densities for targets are added as predictors in the regression model. Table 2 provides the mean semantic scores from the pretest and the mean frequencies in the four conditions for primes and targets.

To prevent strategic effects, we furthermore included 308 filler pairs, so that critical item pairs make up only $10.47 \%$ of all items. Fillers consisted of 50\% real words and 50\% non-words. The non-words are based on those used in Hanique, Aalders, and Ernestus (2013), who constructed their pseudo-verbs by exchanging one or two letters in the

\section{Table 2}

Mean frequencies (Lg10CD) in Experiment 1, extracted from the SUBTLEX-NL database (Keuleers et al., 2010), and mean relatedness scores from the pretest that was performed (ratings were on a seven point scale on which 1 is completely unrelated to the target, and 7 highly related to the target) for the target (the stem + infinitival suffix) and the primes in the Morphologically and Semantically related (MS), only Morphologically related (M), Phonologically related $(\mathrm{Ph})$, and Control $(\mathrm{C})$ conditions. Standard deviations are given in parentheses.

\begin{tabular}{llll}
\hline & Example item & Frequency & Relatedness score \\
\hline Target & bieden 'offer' & $3.31(0.49)$ & - \\
MS prime & aanbieden 'offer' & $2.16(0.63)$ & $5.51(0.70)$ \\
M prime & verbieden 'forbid' & $2.30(0.73)$ & $1.91(0.56)$ \\
Ph prime & bespieden 'spy' & $1.58(0.71)$ & $1.19(0.26)$ \\
C prime & opjagen 'hurry, rush' & $1.97(0.50)$ & $1.12(0.15)$ \\
\end{tabular}


stems of real verbs while preserving the phonotactic constraints and morphological structure of Dutch real verbs. Half of the fillers are complex words, and half of the fillers do not have a prefix, with the nonwords occurring with existing prefixes. All stimuli are presented in the infinitive form (stem $+e n$ ), and all fillers are randomly combined to create prime-target pairs.

\subsubsection{Apparatus}

The stimuli were recorded by an adult female native speaker of Dutch in a sound attenuated booth, using a high-quality microphone. Soundfiles were segmented using Praat (Boersma \& Weenink, 2015) and normalized to a peak amplitude of $70 \mathrm{~dB}$ SPL. The task was implemented in PsychoPy2 (Peirce, 2007). Stimuli were presented auditorily to the participants through Sennheiser HD 280 PRO headphones.

\subsubsection{Procedure}

A continuous lexical decision task was used. The experiment consisted of four lists, with primes of the same target rotated according to a Latin Square design, such that each subject saw every target only once. The task had a random inter-stimulus interval (henceforth ISI) between 800 and $900 \mathrm{~ms}$. The ISI was measured from the end of the sound file or participant response, whichever was later. Stimuli presentation was randomized throughout the experiment for each participant. The experiment consisted of 5 blocks with the possibility for a self-administered break after each block, and a practice trial of 8 items at the beginning of the experiment.

Participants were tested individually in a quiet room. Participants were instructed that they would hear existing and non-existing Dutch verbs, and that they had to make a lexical decision to each word as fast and as accurately as possible. Responses of 'Word' and 'Non-word' were recorded from keyboard button presses. The experiment lasted for approximately $25 \mathrm{~min}$ per participant.

\subsection{Results Experiment 1}

\subsubsection{Modeling}

The data were analyzed as follows. Responses were coded for response type (word/non-word) and response time (RT; measured in ms from the onset of the sound file). Differences in duration of the sound files were included as a predictor in the model. Trials with incorrect responses to primes or targets were discarded, which led to an exclusion of 31 data points out of a total of 1152 trials ( 36 targets * 32 participants). We follow Baayen and Milin (2010) and combine minimal a priori data trimming with post-fitting model criticism. All targets with outlier RTs ( $<100 \mathrm{~ms}$ and $>2000 \mathrm{~ms}$ ) were excluded, as well as the targets for which the prime had an outlier RT. This led to a further exclusion of 17 data points. The RT data were log-transformed, and removal of outliers was done for 5 individual subjects and 3 individual items for which Shapiro-Wilk's tests for normality showed non-Normal distributions, which led to the further removal of 26 data points. In total, a priori data trimming led to the exclusion of 43 observations, or $3.8 \%$.

We analyzed effects on log-transformed RT (our dependent variable) with linear mixed-effects models, using the lme4 package (Bates, Mächler, Bolker, \& Walker, 2015, version 1.1-12) in the R environment (R Core Team, 2016, version 3.3.0). We first fit a model with a maximum random structure. Then, following recommendations by Bates, Kliegl, Vasishth, and Baayen (2015), a principle components analysis on the random-effects structures was performed, using the rePCA function in the RePsychLing package (Baayen, Bates, Kliegl, \& Vasishth, 2015, version 0.0 .4 ), to determine the optimal random structure supported by the data. This ensures that the model is not overly complex or underspecified in its random-effects structure. The analysis resulted in the inclusion of random intercepts for subjects, primes, and targets; random slopes did not improve model fit. The following main effects are included in the model: CONDITION (MS/M/Ph/Control), PRIMEPREFIX (whether the prime includes a separable or inseparable prefix), GROUP, ISI,
Table 3

Mean response times to the targets (in ms), priming effects (in ms), and error rates (number of incorrect responses to targets and primes) per condition. RTs are measured from the onset of the sound file. Priming effect is the RT for the baseline Control condition minus the RT for the MS/M/Ph condition. Standard deviations are given in parentheses.

\begin{tabular}{llll}
\hline Condition & RT target & Priming effect & Inacc. responses \\
\hline Control & $922.56(164.17)$ & $N A$ & 13 \\
MS & $834.08(158.50)$ & $88.48^{* * *}$ & 5 \\
M & $844.18(161.06)$ & $78.38^{* * *}$ & 5 \\
Ph & $904.81(164.12)$ & 17.75 & 8 \\
\hline
\end{tabular}

TARGETFREQUENCY, PRIMEFREQUENCY, TARGETDURATION, PRIMERT, TRIAL, and TARGETNEIGHBORHOODDENSITY. CONDITION is treatment coded with the Control condition as the reference level. PRIMEPREFIX is sum-coded, and TARGETFREQUENCY, PRIMEFREQUENCY, TARGETDURATION, TRIAL, PRIMERT, ISI, and TARGETNEIGHBORHOODDENSITY are Z-scored.

Model criticism was performed on the full model to identify overly influential outliers (Baayen \& Milin, 2010). The model was refitted after excluding data points with absolute standardized residuals exceeding 2.5 standard deviations, which resulted in the exclusion of $23 \mathrm{ob}$ servations (total removed outliers: 97 , or $8.4 \%$ ). The results of the final model after model criticism are presented here. $P$-values are determined using the package lmerTest (Kuznetsova, Brockhoff, \& Christensen, 2016); significant $p$-values are reported at $p<0.05$.

\subsubsection{Results}

An overview of the results is provided in Table 3 and in Fig. 1. Table 3 gives the raw RT data, but note that the analyses are done on the log-transformed RT data (as indicated in Fig. 1). A model summary table is provided in Table 4. Additional models for which the reference level was adjusted can be found in the appendix.

The analysis of the log-transformed RT data revealed a significant facilitation in the MS condition $(\beta=-0.12, p<0.001)$ and in the M condition $(\beta=-0.10, p<0.001)$, compared to the baseline Control (C) condition. No priming was obtained in the $\mathrm{Ph}$ condition $(\beta=-0.02, p=$ 0.123). In addition, and as expected for a lexical decision task, the model revealed a significant effect of TRIAL $(\beta=-0.04, p<0.001)$, showing that participants responded faster (lower RT) as the experiment progressed. The effect of TARGETDURATION was also significant $(\beta=0.07, p<0.001)$, indicating that longer targets were recognized slower, since RT was calculated from the start of the sound file. Similarly, PRIMERT was significant ( $\beta$ $=0.05, p<0.001$ ), showing that how fast a participant responded to the

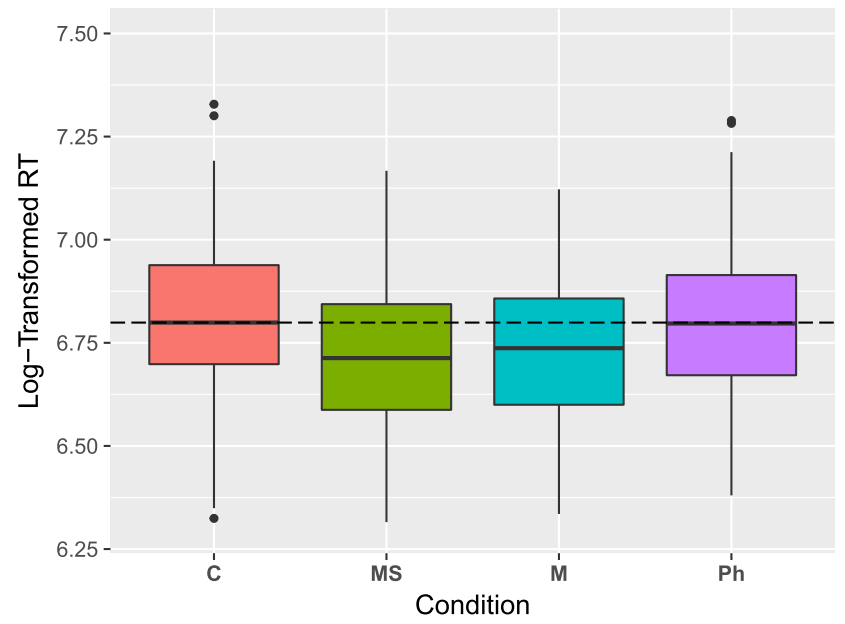

Fig. 1. Log-transformed response times in Experiment 1 for the Morphologically and Semantically related (MS), only Morphologically related (M), Phonologically related (Ph), and Control (C) conditions. 
Table 4

Linear Mixed Effects Model summary for the analysis of RT data in Experiment 1 , with the reference level of PRIMECONDITION set to the Control (C) condition. ${ }^{\text {a }}$

\begin{tabular}{lccc}
\hline & \multicolumn{3}{c}{ Log-transformed RT } \\
\hline Fixed Effects & Estimate $(\beta)$ & $t$-value & $p$-value \\
(Intercept) & 6.81 & 408.747 & $<.001$ \\
Prime Condition (C) & & & \\
$\quad M$ & -0.10 & -8.150 & $<.001$ \\
$M S$ & -0.12 & -9.537 & $<.001$ \\
$\quad$ Ph & -0.02 & -1.540 & .123 \\
Prime Prefix & 0.02 & 2.634 & $\mathbf{. 0 0 8}$ \\
Trial Number & -0.04 & -9.543 & $<.001$ \\
ISI & 0.00 & 0.159 & .874 \\
Target Frequency & -0.02 & -2.631 & $\mathbf{. 0 0 9}$ \\
Prime Frequency & 0.02 & 3.515 & $<.001$ \\
Target Neighborhood Density & -0.01 & -1.272 & .203 \\
Target Duration & 0.07 & 9.831 & $<.001$ \\
Prime RT (log) & 0.05 & 11.041 & $<.001$ \\
& & & \\
Random Effects & $N$ & Variance & St. dev \\
Primes & $143^{\mathrm{b}}$ & 0.0003 & 0.018 \\
Targets & 36 & 0.0009 & 0.030 \\
Subjects & 32 & 0.0057 & 0.076 \\
Residual & & 0.0157 & 0.126 \\
& & & \\
N Datapoints & 1055 & & \\
\hline
\end{tabular}

a Significant $p$-values $(p<0.05)$ are shown bold faced.

b Due to a coding error, the prime 'verbranden' occurred twice in the Control condition, but on different lists: once as the prime for denken in group 3, and once as the prime for dragen in group 4 . This is the reason why the total number of individual primes is 143 , rather than 144 .

prime influenced RTs of the targets: in general, a participant responded slower to a target after they took longer to respond to the prime. Further main effects were found for TARGETFREQUENCY $(\beta=-0.02, p=0.009)$ and PRIMEFREQUENCY $(\beta=0.02, p<0.001)$. This shows that participants responded faster to higher frequency targets than to lower frequency targets, but that they recognized a target slower after hearing a higher frequency prime. Furthermore, whether the prime includes a separable or inseparable prefix (PRIMEPREFIX) also turned out to be a significant predictor $(\beta=$ $0.02, p=0.008)$.

We performed a further planned comparison by resetting the reference level to the $\mathrm{M}$ condition. This allowed us to make additional comparisons between MS and M, and between $\mathrm{Ph}$ and M. The first comparison answers the question whether there is an additional effect of transparency on top of morphological effects; the second comparison if there is an additional effect of morphology on top of phonological effects. This separate model showed that there was no significant difference in the magnitude of priming between the MS and the M conditions ( $\beta=-0.02, p=0.169$ ), suggesting equal magnitudes of priming in morphologically related conditions regardless of semantic transparency. In addition, the $\mathrm{Ph}$ condition showed significantly longer RTs compared to the M condition $(\beta=0.08, p<0.001)$.

\subsection{Experiment 1 discussion}

The goal of this experiment was to investigate what role morphological structure plays in the processing of Dutch complex verbs, while distinguishing morphological effects from semantic (transparency) and phonological effects. The results show that the primes in both the semantically transparent MS condition (aanbieden 'offer') and the semantically opaque $\mathrm{M}$ condition (verbieden 'forbid') significantly facilitate recognition of their stem (bieden 'offer'). The difference in priming effect between the MS and M conditions ( 88.48 and $78.38 \mathrm{~ms}$, respectively) was not significant. These results fail to detect an effect of semantic transparency in Dutch complex verbs. In contrast to morphologically related prime-target pairs, purely phonologically related prime-target pairs (Ph; bieden 'offer' $\rightarrow$ bespieden 'spy') did not show a significant priming effect. The comparison between the $\mathrm{M}$ and $\mathrm{Ph}$ conditions shows that morphological effects are not just due to phonological overlap: the magnitude of priming is clearly and significantly distinct from the priming effects in the $\mathrm{M}$ condition.

These results are in line with the results for German prefixed verbs (Smolka et al., 2009; Smolka et al., 2014), in which it was also found that both morphologically and semantically related (zubinden 'tie') and morphologically related but semantically opaque (entbinden 'deliver') prefixed verbs prime their stem (binden 'bind'). The German experiments measured RTs to visually presented targets (in purely visual and cross-modal paradigms), while the present study used auditory targets. The results show that morphological priming in the absence of semantic transparency can be obtained for complex verbs not only in German, but also in Dutch, and not only in a visual or cross-modal priming paradigm, but also in an auditory-auditory paradigm.

Finally, the results show faster responses to verbs following inseparable prefixed verbs than following separable prefixed verbs. A similar finding is reported in Smolka et al. (2019) for German prefixed verbs. The authors suggest that this difference may result from a frequency effect because the inseparable prefixed verbs used in their study were generally more frequent than the separable prefixed verbs used. This is, prima facie, also the case for the stimuli in our study: inseparable prefixed verbs have a slightly higher frequency (mean $=2.10$, sd $=0.76)$ than separable prefixed verbs $($ mean $=1.82$, $s d=0.74$ ). However, as pointed out to us by a reviewer, frequencies for separable prefixed verbs are not reliable, as they do not include the counts of the cases in which the verb and prefix are separated. The true frequency of the separable prefixed verbs may therefore be higher than what is standardly reported. While our experiment was not designed to investigate differences between separable and inseparable prefixed verbs, we note that it is possible that the difference is caused by the separability of the prefix. As pointed out by Schreuder (1990), what a finite verb form means may remain unclear until the whole utterance has been processed in the case of separable prefixed verbs, since the prefix is stranded at the end of the sentence. Therefore, speakers of Dutch (and German) might have learned that early commitment to the meaning of these verbs is not favorable. This could conceivably have a general effect on the target recognition in a primed lexical decision experiment. Of course, since in our stimuli the prefix occurs before the stem, an account based on unfavorable early commitment would require additional elaboration in order to predict the observed pattern.

In sum, the results of this experiment show that the semantically opaque $M$ verbs significantly facilitate their stem. This suggests that semantic relatedness is not a precondition for the occurrence of morphological priming in Dutch prefixed verbs. In order to further investigate the (lack of) semantic effects, we include a Semantic condition in our next experiment (e.g., bieden 'offer' $\rightarrow$ verlenen 'give, grant') and manipulate the number of intervening items between prime and target.

\section{Experiment 2}

Our second experiment aims to further control for semantic effects in two ways. First, we include a Semantic condition (S) in which the primes and targets are semantically, but not morphologically or phonologically related to each other. These primes typically form synonyms of the targets (such as the prime aanschouwen 'see, watch' for the target kijken 'look, watch'), but in some cases the prime is not a synonym but still highly related in meaning to the target. All $S$ primes are prefixed verbs. The addition of this condition allows us to investigate the extent to which the priming effects in the MS condition might be due to semantic relatedness. Moreover, the $\mathrm{S}$ condition allows us to rule out the possibility that the priming effects in the $\mathrm{M}$ condition are due to semantic priming via a semantically transparent activation of the meaning of the stem in M. Our participants might parse the semantically opaque words as having a semantically transparent meaning, even though we constructed our $\mathrm{M}$ condition in a way that, in principle, excludes the possibility of a 
transparent secondary meaning for the M stimuli (in contrast to the verbs in Zwitserlood et al., 2005 which are ambiguous between an opaque and a transparent sense as part of the experimental design). If the priming effects we find for $\mathrm{M}$ are due to our participants decomposing the $\mathrm{M}$ condition based on a (non-existing) transparent meaning of the prefix and stem, we expect to find priming in $\mathrm{M}$ that is similar to $\mathrm{S}$.

Second, in case we find no difference in priming effects for MS, M, and $\mathrm{S}$ at an immediate distance, we include non-immediate priming as a tool to track the time-course with which different types of information (semantic/ morphological) become available during word recognition and lexical access. In a non-immediate priming experiment, several words may intervene between the prime and its target, thereby prolonging the time interval between prime and target. Previous priming studies have shown that semantic priming effects decay more quickly over time than morphological effects (visual modality: Bentin \& Feldman, 1990; Feldman, 2000, i.a.; auditory modality: Kouider \& Dupoux, 2009; Marslen-Wilson \& Tyler, 1998). Therefore, if our M, MS, and S conditions show similar priming effects at an immediate distance (and to the extent that morphological and semantic factors indeed exhibit different patterns over time), a long-distance priming paradigm forms a valuable tool to tease apart the semantic and morphological contributions to the word recognition process. Since semantic priming effects decay more quickly over time than morphological effects, we predict that, if all conditions induce priming effects at an immediate distance (0-lag), we will see a clear difference between the conditions at a distance (5-lag) with the MS (priming not only semantically but also morphologically) and $M$ verbs facilitating recognition of the target to a greater extent than the $S$ verbs.

\subsection{Method Experiment 2}

\subsubsection{Participants}

Participants were 40 adult native speakers of Dutch, most of whom were students or recent alumni of the University of Amsterdam (mean age $=28.81$; $\mathrm{sd}=11.35$ ). All were raised monolingual, and reported having no reading, hearing, or other language disorders. Participants were paid a small fee (5 euros) for their participation.

\subsubsection{Materials}

This experiment includes the M (morphologically related, semantically opaque) and MS (morphologically and semantically related) conditions that were included in Experiment 1. Since the Phonological effects in Experiment 1 did not reach significance and were clearly distinct from the morphological effects, we replace the Ph (phonologically related) condition with a Semantic (S) condition, in which the prime and target are semantically related, but not phonologically or morphologically. Finally, we again include a Control (C) condition of prime-target pairs that are neither phonologically, semantically, nor morphologically related to their base. The conditions and example items are given in Table 5; all items can be found in the appendix.

In total, the experiment includes 40 base verbs which function as the targets. The base verbs are the same as were used in Experiment 1, with the addition of four verbs (keren, komen, roeren, spreken) and their primes, as well as the primes for the $S$ condition. Furthermore, we changed some items in the other conditions because they had similar stems as the added items. Every subject heard 10 items per condition, half of which are presented at an immediate distance, and half at a 5item-lag between prime and target.

As with Experiment 1, semantic relatedness scores were established by a pre-test, the details of which can be found in the appendix. Table 6 provides prime and target mean frequencies and mean semantic relatedness scores per condition.

Experiment 2 includes 180 filler pairs, so that the critical items make up $18.2 \%$ of all items. We included fewer filler items in this experiment than we did in Experiment 1 because of the addition of the distance manipulation, due to which participants are less likely to become aware of the critical manipulation. Only half of the targets are
Table 5

Conditions and example critical items in Experiment 2, for the target (the stem + infinitival suffix) and the primes in the Morphologically and Semantically related (MS), only Morphologically related (M), Semantically related (S), and Control (C) conditions. Half of the items are presented at an immediate distance, and half at a distance of 5 intervening items between prime and target.

\begin{tabular}{|c|c|c|c|c|}
\hline Target & MS prime & M prime & S prime & C prime \\
\hline bieden & aanbieden & verbieden & verlenen & opjagen \\
\hline 'offer' & 'offer' & 'forbid' & 'give, grant' & 'hurry, rush' \\
\hline schieten & beschieten & opschieten & afvuren & bezoeken \\
\hline 'shoot' & 'fire on/at' & 'hurry up' & 'fire' & 'visit' \\
\hline werpen & afwerpen & ontwerpen & weggooien & uitdraaien \\
\hline 'throw' & 'throw off' & 'design' & 'throw away' & 'print out' \\
\hline
\end{tabular}

Table 6

Mean frequencies (Lg10CD) in Experiment 2, extracted from the SUBTLEX-NL database (Keuleers et al., 2010), and mean relatedness scores from the pretest that was performed (ratings were on a seven point scale on which 1 is completely unrelated to the target, and 7 highly related to the target) for the target (the stem + infinitival suffix) and the primes in the Morphologically and Semantically related (MS), only Morphologically related (M), Semantically related (S), and Control (C) conditions. Standard deviations are given in parentheses.

\begin{tabular}{llll}
\hline & Example item & Frequency & Relatedness score \\
\hline Target & bieden 'offer' & $3.29(0.54)$ & - \\
MS prime & aanbieden 'offer' & $2.18(0.63)$ & $5.55(0.64)$ \\
M prime & verbieden 'forbid' & $2.25(0.75)$ & $1.89(0.56)$ \\
S prime & verlenen 'give, grant' & $2.06(0.86)$ & $5.45(0.77)$ \\
C prime & opjagen 'hurry, rush' & $1.93(0.52)$ & $1.12(0.52)$ \\
\hline
\end{tabular}

presented immediately after their prime, which amounts to $9.09 \%$ of all items. Of the 360 filler items in total, 140 were real words and 220 were non-words. Half of all fillers are complex words, and half of the fillers do not have a prefix (the non-words occur with existing prefixes). The fillers are selected from the fillers that were used in Experiment 1, and are randomly combined to create prime-target pairs.

\subsubsection{Apparatus}

The method of recording, implementation of the task, and presentation of the stimuli are identical to Experiment 1.

\subsubsection{Procedure}

As in Experiment 1, a continuous lexical decision task was used. Stimuli were presented at an immediate distance (0-lag) and at a distance of five intervening items between prime and target (5-lag). Lexical decisions were made to all items, including the items intervening between primes and targets. The experiment consisted of eight lists, with primes of the same target rotated according to a Latin Square design, such that each subject saw every target only once. Distance was manipulated between-subjects, such that different participants saw primes at either 0- or 5-lags. Participants could take two self-administered breaks during the experiment. The experiment included a practice trial of 8 items at the beginning of the experiment. The task had a random ISI between 600 and $800 \mathrm{~ms}$, and lasted for approximately $15 \mathrm{~min}$. The ISI was slightly reduced compared to Experiment 1 to make the task shorter, and consequently less taxing for participants. The rest of the procedure was the same as in Experiment 1.

\subsection{Results Experiment 2}

\subsubsection{Modeling}

The modeling for Experiment 2 was similar to Experiment 1. Discarding of incorrect responses to primes and targets led to an exclusion of 99 out of 1600 critical items. Minimal a priori data trimming (Baayen \& Milin, 2010) led to a further exclusion of 28 data points for 
targets with outlier RTs $(<100 \mathrm{~ms}$ and $>2000 \mathrm{~ms})$, as well as all targets for which the prime had an outlier RT. The RT data were log-transformed, and further outlier removal was done for 10 individual subjects and 1 item for which Shapiro-Wilk's tests for normality showed nonNormal distributions (leading to the further removal of 19 data points). In total, a priori data trimming led to an exclusion 47 observations, or $3.13 \%$ of the data after exclusion of inaccurate responses. The effects on log-transformed RT are analyzed with linear mixed-effects models (Bates et al., 2015). Random effect optimization (Bates et al., 2015) indicated that the participant-related and target-related variance component for the MS condition significantly improved model fit, while the other factors for condition did not. This resulted in a random effects structure with by-subject and by-target slopes for the MS condition, as well as random intercepts for subjects, primes, and targets.

The following main effects are included in the model: PRIMECONDITION (MS/M/Ph/C), DISTANCE (0-lag, 5-lag), and their interaction, PRIMEPREFIX (whether the prime includes a separable or inseparable prefix), TRIAL, ISI, TARGETFREQUENCY, PRIMEFREQUENCY, TARGETNEIGHBORHOODDENSITY (PTAN), and TARGETDURATION. PRIMECONDITION is treatment coded with the Control condition as the reference level, DISTANCE is treatment coded with 0-lag as the reference level, and PRIMEPREFIX is sum-coded. TRIAL, ISI, TARGETFREQUENCY, PRIMEFREQUENCY, TARGETNEIGHBORHOODDENSITY, and TARGETDURATION are z-scored. As for Experiment 1, model criticism was performed on the full model to identify overly influential outliers (Baayen \& Milin, 2010), which resulted in the exclusion of 29 observations, after which the model was refitted.

\subsubsection{Results}

Table 7 provides an overview of the raw RTs and error rates for all four conditions at a 0-lag and at a 5-lag distance. Figs. 2 and 3 give the mean response times (log $\mathrm{ms}$ ) in all four conditions at both lags.

At 0-lag, the analysis of the log-transformed RT data revealed a significant priming effect for the MS condition $(\beta=-0.06, p<0.001)$ and for the M condition $(\beta=-0.06, p<0.001)$, compared to the Control condition. No significant difference was found between the Semantic condition and the Control condition ( $\beta=-0.01, p=0.365$ ). In addition, and as expected for a lexical decision task, the model revealed a significant effect of TRIAL $(\beta=-0.02, p=0.002)$, showing that participants responded faster as the experiment progressed, and of TARGETDURATION $(\beta=0.06, p<0.001)$, indicating that longer targets were recognized slower since RT was calculated from the start of the sound file. In contrast to the results of Experiment 1, PRIMEPREFIX did not show a significant effect $(p=0.842)$. A summary of this model is provided in Table 8 . Additional models can be found in the appendix.

Further planned pairwise comparisons of PRIMECONDITION at a 0-lag were obtained by setting the reference level to MS using the same model, while keeping the reference level for DISTANCE set to 0-lag. This allowed us to see if there is an additional effect of morphology on top of semantics (MS-S), and if there is an additional effect of semantic transparency (MS-M), at a 0-lag.

\section{Table 7}

Mean response times (RTs) to the targets (in ms), priming effects (in ms), and error rates (number of incorrect responses to targets and primes) in Experiment 2 , per condition and per lag ( 0 and 5$)$. RTs are measured from the onset of the sound file. Priming effect is the RT for the baseline Control condition minus the RT for the MS/M/S condition. Standard deviations are given in parentheses.

\begin{tabular}{lllll}
\hline Condition & Lag & RT target & Priming effect & Inacc. responses \\
\hline MS & 0 & $913.53(168.62)$ & $54.10^{* * *}$ & 4 \\
M & 0 & $906.47(159.25)$ & $61.16^{* * *}$ & 4 \\
S & 0 & $950.63(161.49)$ & 17.00 & 14 \\
Control & 0 & $967.63(160.74)$ & - & 12 \\
MS & 5 & $981.48(180.11)$ & -14.35 & 15 \\
M & 5 & $965.69(165.18)$ & 1.45 & 13 \\
S & 5 & $977.55(163.50)$ & -10.41 & 20 \\
Control & 5 & $967.13(168.39)$ & - & 17 \\
\hline
\end{tabular}

The model showed that, at a 0-lag, there was no significant difference between MS and M $(p=0.708)$, while there was a significant difference between MS and $S(\beta=0.04, p=0.002)$.

With respect to the different lags used, the two-way interaction between PRIMECONDITION and DISTANCE in the first model indicates that the priming effect (comparing the critical condition to $\mathrm{C}$ ) for MS at a 0-lag is significantly larger compared to the priming effect for MS at a 5-lag distance $(\beta=0.06$, $p<0.001$ ), and the same holds for the priming effect for $\mathrm{M}$ at a 0 -lag and at a 5-lag distance $(\beta=0.05, p=0.002$ ), while no difference was found for $S$ $(p=0.156)$. The interaction in the second model furthermore indicates that the decay for MS between the 0-lag and 5-lag does not significantly differ from the decay for the M condition ( $p=0.597)$.

Finally, to take a further look at the effects at a 5-lag, we fit a model with the same model structure, in which we set the reference level of DISTANCE to 5-lag and the reference level of PRIMECONDITION to the $\mathrm{C}$ condition. This reveals that none of the effects for PRIMECONDITION were significant at a 5-lag distance (MS: $p=0.612$; M: $p=0.575$; S: $p=0.274$ ).

\subsection{Experiment 2 discussion}

The goal of our second experiment was to further investigate to what extent semantic relatedness plays a role in the processing of morphologically complex words. At a 0-lag, the results replicate the results in Experiment 1, in that the primes in both the semantically transparent MS condition (aanbieden 'offer') and the semantically opaque $\mathrm{M}$ condition (verbieden 'forbid') significantly facilitate recognition of their stem (bieden 'offer'), with no difference between the amount of facilitation in both conditions. In contrast to morphological priming, purely semantically related prime-target pairs (verlenen 'give, grant' $\rightarrow$ bieden 'offer') did not show a significant priming effect at a 0 lag. The comparison between the MS and S conditions shows that the morphological effect that we see in the MS condition is larger than we would expect from mere semantic overlap. This allows us to make a stronger inference regarding the $\mathrm{M}$ condition as well, as the absence of semantic effects shows that the priming in the $\mathrm{M}$ condition is not due to an attempt of our participants to give a semantically transparent parse to the complex verbs in this condition.

While we expected to find a gradual drop-off in the priming effects, instead, none of the effects reach significance at a 5-lag. It is likely that the lag we used ( 5 intervening items between prime and target) was too large to see a gradual drop-off. This is surprising considering earlier results with long-distance priming in the auditory domain by MarslenWilson and Tyler (1998) (12 intervening items), Kouider and Dupoux (2009) (18 to 144 intervening items), and Wilder et al. (2019) (0, 1, and 5 intervening items). However, these studies used shorter (often monosyllabic) words, whereas our words were two or three syllables in length, and were therefore longer. We suspect that using a lag of one or two intervening items might have shown the drop-off in the facilitation effects, while at a 5-lag all effects have already disappeared.

Moreover, it is surprising that we did not find significant semantic effects at a 0-lag. The rationale of including prime-target pairs that are presented at a 5-lag, was that we expected to see semantic effects at a 0lag. However, Smolka et al. (2014) report a similar finding for verbverb pairs. In their Experiment 1 (purely visual) and Experiment 2 (cross-modal), the $\mathrm{S}$ condition also did not show significant facilitation (and similar findings are reported in Smolka et al., 2009). In their Experiment 3 (purely visual), Smolka et al. (2014) added semantically related noun pairs (such as Biene 'bee' $\rightarrow$ Honig 'honey' and Onkel 'uncle' $\rightarrow$ Tante 'aunt'), in addition to the semantically related verbs that were used in the previous experiments. Interestingly, now the semantically related verbs (as well as the nouns) showed significant facilitation, which was equally strong as the morphologically related (MS and M) conditions. The authors argue that the top-down procedure participants used to complete the task is, in fact, sensitive to detecting semantic influences, and that the semantically related verbs can be primed under conditions that promote semantic priming across mixed word classes. 

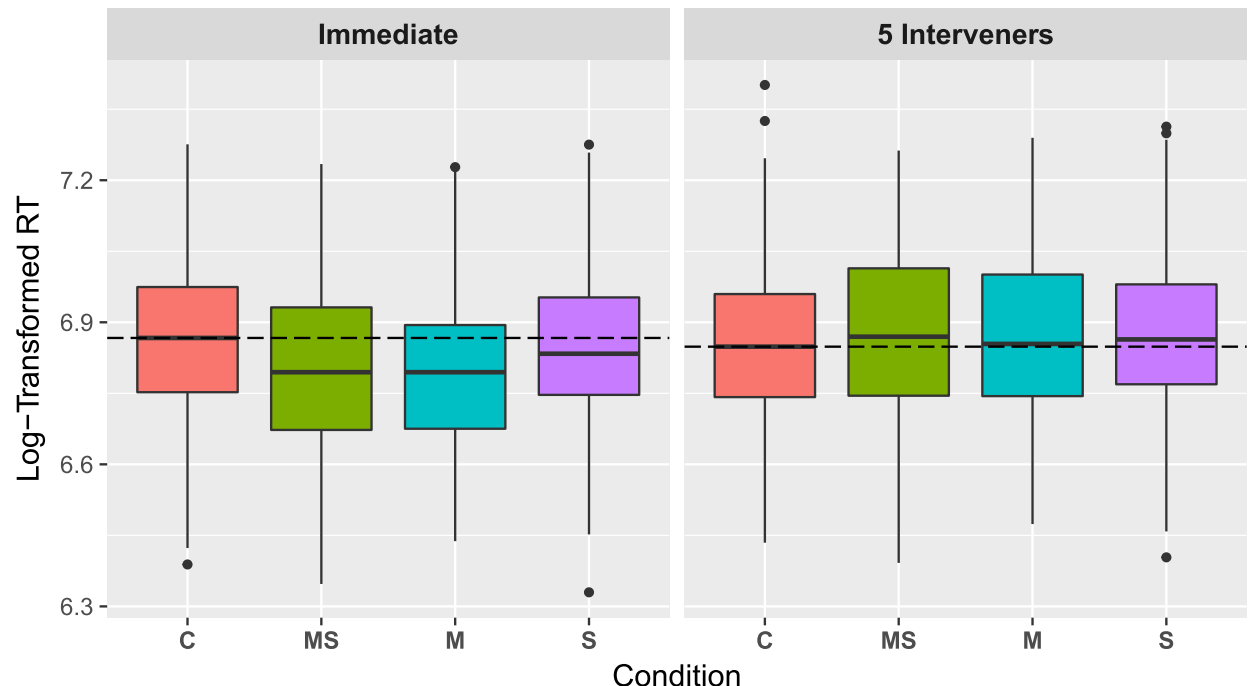

Fig. 2. Log-transformed RTs in Experiment 2 (after data trimming) for the Morphologically and Semantically related (MS), only Morphologically related (M), Semantically related (S), and Control (C) conditions, over a distance of zero intervening items (left), and five intervening items (right) between prime and target.

Moreover, while behavioral data are inconsistent when it comes to verb-verb associative priming, electrophysiological data indicate strong semantic priming effects in terms of N400 modulations (Smolka, Khader, Wiese, Zwitserlood, \& Rösler, 2013; Smolka et al., 2015). It is important to note that the lack of semantic facilitation stresses the effect of morphological relatedness even more: the lack of semantic facilitation in the $\mathrm{S}$ condition clearly demonstrates that the strong morphological facilitation effects in the MS condition were not due to meaning overlap between prime and target.

Finally, when we compare the magnitude of priming effects in the MS and M conditions between Experiment 1 and Experiment 2 at immediate distance, we see numerically slightly larger effects in Experiment 1 (Experiment 1: 88.48 and $78.38 \mathrm{~ms}$, Experiment 2: 54.10 and $61.16 \mathrm{~ms}$ ). The most likely explanation for this difference is the shorter ISI that was used in Experiment 2 (Experiment 1: 800-900 ms; Experiment 2: 600-800 ms).

\section{General Discussion}

The experiments presented in this paper investigate the processing of morphologically complex verbs in Dutch. They address the specific question of what effects the semantic opacity of a prefixed verb has on its relation to its stem. The results of the two experiments show equal and robust priming in the semantically transparent MS and the semantically opaque $\mathrm{M}$ conditions (at a 0-lag), while no significant priming effects were found for only phonologically related items (Experiment 1) or only semantically related items (Experiment 2). The results for the Semantic and Phonological conditions indicate that the effects in the MS and M conditions cannot be attributed to mere semantic or phonological overlap.

Our results are in line with the findings for German by Smolka et al. (2009, 2014, 2015, 2019). They also extend the finding of morphological processing independent of semantic transparency reported in De Grauwe et al. (2019). Importantly, in comparison to De Grauwe et al. (2019), the present experiments employ a more powerful within-items rather than between-items design, and, crucially, our experiments include phonological and semantic controls that allowed us to rule out the possibility that facilitation was the result of form and/or meaning overlap. Having established that opaque complex words are truly related to their embedded stem, we leave it for future research to investigate further questions regarding the temporal activation of meaning representations for opaque versus transparent complex words. This relates to the contrasts in semantic/associative priming between Dutch opaque and transparent words that have been reported (De

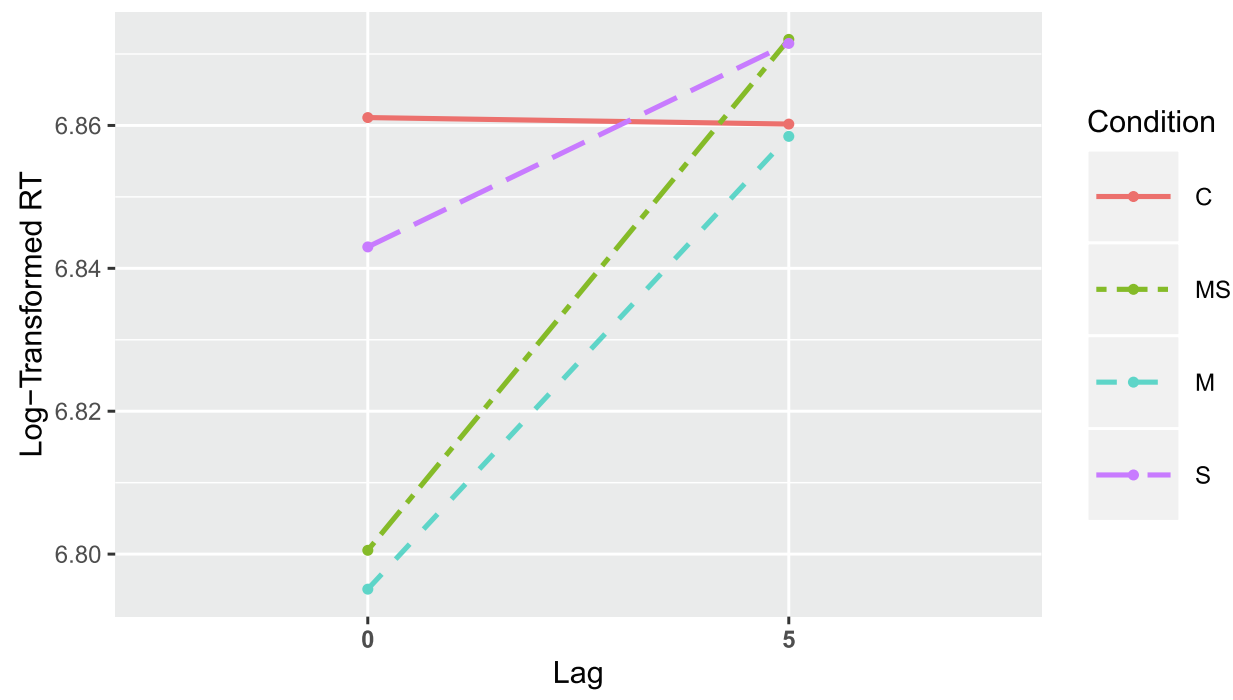

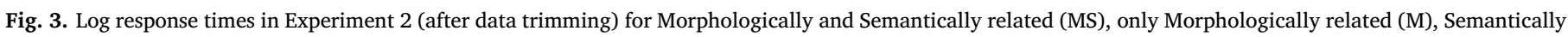
related (S), and Control (C) conditions, at the two lags used between prime and target. 
Table 8

Linear Mixed Effects Model summary for the analysis of RT data in Experiment 2 , with the reference level of PRIMECONDITION set to the $C$ condition, and the reference level of DISTANCE set to 0-lag. ${ }^{\text {a }}$

\begin{tabular}{|c|c|c|c|}
\hline \multirow[b]{2}{*}{ Fixed Effects } & \multicolumn{3}{|c|}{ Log-transformed RT } \\
\hline & Estimate $(\beta)$ & t-value & p-value \\
\hline (Intercept) & 6.86 & 363.411 & $<.001$ \\
\hline \multicolumn{4}{|l|}{ Prime Condition (C) } \\
\hline MS & -0.06 & -3.848 & $<.001$ \\
\hline$M$ & -0.06 & -4.981 & $<.001$ \\
\hline$S$ & -0.01 & -0.906 & .365 \\
\hline Distance 5-lag & 0.00 & 0.188 & .851 \\
\hline Prime Prefix & 0.00 & 0.199 & .842 \\
\hline Trial Number & -0.02 & -3.165 & .002 \\
\hline ISI & 0.00 & 0.560 & .576 \\
\hline Target Frequency & -0.01 & -1.910 & .056 \\
\hline Prime Frequency & 0.00 & 1.111 & .267 \\
\hline Target Neighborhood Density & -0.01 & -1.948 & .051 \\
\hline Target Duration & 0.06 & 9.016 & $<.001$ \\
\hline Prime Condition MS: Distance 5-lag & 0.06 & 3.627 & $<.001$ \\
\hline Prime Condition M: Distance 5-lag & 0.05 & 3.100 & .002 \\
\hline Prime Condition S: Distance 5-lag & 0.03 & 1.419 & .156 \\
\hline Random Effects & $N$ & Variance & St. dev \\
\hline Prime Intercept & 160 & 0.0000 & 0.000 \\
\hline Targets & 40 & & \\
\hline Intercept & & 0.0016 & 0.040 \\
\hline MS slope & & 0.0021 & 0.046 \\
\hline Subjects & 40 & & \\
\hline Intercept & & 0.0095 & 0.098 \\
\hline MS slope & & 0.0003 & 0.016 \\
\hline Residual & & 0.0137 & 0.117 \\
\hline N Datapoints & 1425 & & \\
\hline
\end{tabular}

${ }^{\text {a }}$ Significant $p$-values $(p<0.05)$ are shown bold faced.

Grauwe et al., 2019; Zwitserlood et al., 2005). Investigating the activation of morphological representations versus the activation of semantic representations (and their temporal dynamics) may also shed further light on reported early whole-word effects (Kuperman et al., 2009, 2010; Schreuder et al., 2003).

Also noteworthy is the fact that the experiments in the present study were conducted in the intra-modal auditory modality. Our results, therefore, show that morphological effects for truly morphologically derived words are not restricted to the visual recognition of target words, but extend to auditory target recognition as well. This rules out the possibility that apparent effects of morphological relatedness are due to properties of the orthographic system (cf. Rastle et al., 2004; Rastle \& Davis, 2008). In addition, and as argued in Section 1.3, the visual and auditory modalities might very well provide different windows on phenomena of interest; thus, the consistency between earlier visual and cross-modal decomposition effects in German and the current intra-modal auditory effects in Dutch is of interest in its own right.

\subsection{Implications for models of the mental lexicon}

A long-standing idea in both linguistic and psycholinguistic theories is that irregular word formation processes (that is, irregular morphophonological forms and non-predictable meanings) are represented differently from regular word formation processes (that is, morphophonologically predictable and semantically transparent). The lexicalist position, adopted by various linguistic theories, is particularly relevant in this respect (for a review see Carstairs-McCarthy, 1992). Different lexicalist theories take a wide range of positions on a number of important matters; however, they tend to agree that while morphological rules play some role in regular word formation processes, irregular words that appear to be complex are represented differently. In many theories, they must be listed as unanalyzable wholes in the lexicon. A strong current emerging in more experimentally-oriented approaches also takes a similar stance on this issue, as discussed below.

Our results are incompatible with theories that make semantic overlap a precondition of morphological relatedness, and favor theories that do not have this property. In the sections below, we review some of the most important positions that are implicated in this divide between theories. However, before looking at the implications for particular models, some comments are in order about the scope of the argument that is being developed; in particular, concerning the question of the role of meaning overlap in morphological relatedness effects on the one hand, versus the question of morphological decomposition on the other. For our purposes, what is most relevant about such theories is not their stance on whether a word is decomposed into constituent morphemes or not; rather, it is the question of whether regular and irregular formations are morphologically related to their stems in the same way. Questions about decomposition and relatedness are often closely connected, but they can be disentangled from each other. With respect to the materials used in this paper, it could be asked both (i) whether e.g., verbieden ('forbid') is decomposed into a prefix ver- and a part bieden, and (ii) whether bieden in verbieden is the same morpheme that occurs as free-standing bieden.

While the decomposition question arises in the case of verbs like verbieden, there are clear reasons to think that at least half of our prefixed verbs must be represented as separate pieces. In particular, separable prefixes, like aan in aanbreken ('open, begin; lit. to-break'), may be separated from the verb stem by, in principle, any number of clauses due to the 'verb second' effect in Dutch main clauses. For instance, the separable prefix in the verb op-staan ('get up') in Zij staan morgen wat vroeger op ('They get up somewhat earlier tomorrow') appears sentence finally and is separated from the finite verb (cf. Den Besten, 1983; Schreuder, 1990). About half of our stimuli occur with separable prefixes, such that the question of decomposing a word into a stem and an affix is not a central concern: they can be separated syntactically, and are clearly two pieces.

For the reasons outlined in the introduction, our main focus in this paper is on the question of morphological relatedness: we find evidence for relatedness between prefixed verbs and their stems that is independent of semantic overlap, and not due to phonological similarity. How such relatedness effects are to be accounted for is a complex question. As noted above, it is evident that our results are not compatible with models which assume that semantic transparency is a precondition for relatedness. The models that our results are compatible with, Full-Decomposition models as well as versions of a Discriminative Learning model, share the idea that semantic overlap is not required for relatedness but differ along a number of other interesting dimensions, including basic architectural assumptions. For this reason, we treat them separately in Sections 4.1 .2 and 4.1.3, respectively. General conclusions are presented in Section 4.2.

\subsubsection{Semantic relatedness as a precondition for morphological effects}

Many models of the mental lexicon view semantic overlap as a precondition for relatedness. These models do not predict morphological effects in the absence of semantic transparency, and are therefore incompatible with the present findings for Dutch.

For instance, according to a Supralexical model (Giraudo \& Grainger, 2003, 2001; Voga \& Giraudo, 2009), there is an initial stage of whole-word processing followed by a later stage of decomposition in which morphemes receive activation from the whole-word representation. The supralexical account predicts that morphological priming only occurs for semantically transparent prime-target pairs, since only these share representations at the morphemic level (Diependaele et al., 2005).

Similarly, parallel Dual-Route models are not compatible with our findings. Dual-Route models propose that both decomposition and wholeword access can take place, and that the route taken depends on the type of word that is being accessed. The Morphological Race Model (Frauenfelder \& Schreuder, 1992, see also Baayen et al., 1997), for instance, posits that both ways of accessing a complex word, through decomposition and through whole-word access, are in competition. The winner of the 'race' is determined mainly by the frequency and the 
phonological and semantic transparency of the word to be accessed. Transparent low frequency words have the highest chance of winning the 'decomposition route', while high frequency words and semantically opaque words are accessed through whole-word lexical entries. Therefore, semantically opaque words as the ones used in the present study are not expected to significantly prime their stem under this account, since these words are most likely to be accessed through their whole-word forms.

Our findings are also incompatible with parallel-distributed connectionist models (PDP: Gonnerman et al., 2007), which argue that morphemic structure emerges when stable sub-patterns develop in response to the consistent co-occurrence of orthographic, phonological and semantic information (e.g., Plaut \& Gonnerman, 2000; Raveh, 2002; Seidenberg \& Gonnerman, 2000). Morphological structure in such models has no independent status. Rather, putatively morphological effects emerge from a learned mapping between orthography, phonology, and semantics. Morphological effects are therefore predicted to occur only for semantically compositional words (stemming from the joint contribution of formal and semantic similarity), and the strength of morphological effects should diminish as the semantic similarity between the morphologically related words decreases.

\subsubsection{Full-decomposition}

One type of model of the mental lexicon that can offer a straightforward explanation for our findings is centered on morphological decomposition, and the idea that complex words are represented such that there is representation and processing of morphology that is independent of semantics and phonology (Smolka et al., 2014, 2019; Stockall \& Marantz, 2006; Taft \& Forster, 1975; Taft, 1979; Taft, 2004; Fruchter \& Marantz, 2015, i.a.). The most familiar versions of such models, often termed FullDecomposition, adopt the further assumption that morphemes are discrete objects in memory. When fleshed out, some other processing stages in addition to decomposition are identified as well. For example, Taft (1979, 2004) argues that complex visual words are recognized via a multi-stage process of decomposition into their component morphemes, look-up of the lexical entries of the morphemes (the activation of morphemes as objects in memory), and recombination of the separate morphemes into the complex form (see also Fruchter \& Marantz, 2015; Taft \& Forster, 1975; Wilder et al., 2019).

Full-Decomposition models predict relatedness effects between aanbieden ('offer')/ verbieden ('forbid') and bieden ('offer') because these complex words are decomposed so that they contain bieden. In other words, bieden (or perhaps bied if we abstract away from the infinitival morpheme) has a single representation in memory that is activated regardless of whether the word form it appears in has a transparent or opaque meaning. Morphological priming in a Full-Decomposition model is, therefore, priming via reactivation (Stockall \& Marantz, 2006). The prime verbieden activates the morpheme bieden, which remains active and is therefore above its resting level of activation when the target bieden is encountered. Since both prime and target contain the same morpheme, regardless of semantic transparency, recognition is predicted to be facilitated. The key notion for Full-Decomposition models is the independence of morphological representation from the semantics and phonology of a particular word in which a morpheme might appear.

What it means for morphology to be independently represented looks somewhat different for functional versus lexical morphemes. Beginning with the former, a useful place to start is with divergences from the simplest 'one-form, one-meaning' scenario. The well-studied past-tense morphology of English provides suitable examples. While the default past tense form is (orthographic) -ed, past tense is also expressed with $-t$ (as in bend/bent), with no overt realization (hit/hit), and with various combinations of what look like morphemes, plus stem changes (tell/told; bring/brought). Whatever one says about the analysis of these different relations, all of the right-hand members of these pairs have the same syntactic and semantic distribution: they all occur in past tense contexts. Their difference in form suggests an abstraction like [+ past] that exists independent of the particular phonological changes that express it. The same considerations apply to words that do not share a common meaning. While past tense might be a typical meaning for the forms in question, they also appear in other contexts, such as irrealis ( $I$ wish I worked at a tire factory), sequence of tense (Mary said that she was in the office), politeness (Did you want fries with that?), and many others. The appearance of past tense forms that abstract away from a particular meaning and sound, is therefore taken to correspond to a feature like [+ past], that is represented independent of form and meaning (for additional discussion, see Bacovcin et al., 2017; Goodwin Davies, 2018; Goodwin Davies et al., submitted for publication; Marantz, 2013).

While the example of [+ past] is about affixes, the same holds for the stems in irregular past tense verbs: verbs like leave/left and bring/ brought can be decomposed into a shared part, that is the stem, regardless of phonological idiosyncracies (see Stockall \& Marantz, 2006). Similarly, for the meaning side, words like understand and stand share a stem, regardless of semantic idiosyncracies. The same sorts of considerations have also been applied in the study of transparency and opacity in compounds; see for instance Fiorentino and Poeppel (2007) for a representative view.

In summary, a Full-Decomposition model is able to explain the results reported here by treating words as sharing the same parts. Because these parts have an existence that is independent of (though crucially related to) semantics and phonology, relatedness effects arise even when there is no overlap in meaning between the prime and the target. Regarding the scope of this model's predictions, we note that a Full-Decomposition model is not committed to exactly the same level of facilitation for opaque and transparent pairs at every stage of processing; semantic inhibition of the stem in opaque words is expected to occur at some point in the process of word recognition. Further investigation using the types of stimuli employed in this study might be able to disentangle these different processing stages, and identify differences between the processing of opaque and transparent complex words.

\subsubsection{Discriminative learning}

As pointed out to us by a reviewer, approaches employing different types of discriminative learning (henceforth DL) also appear to predict relatedness effects independent of semantic overlap. Baayen et al. (2011) propose a computational model for morphological processing in visual word recognition, based on naive discriminative learning (NDL). In this model, orthographic representations of letter unigrams and bigrams ('cues') are mapped directly onto semantic representations ('outcomes'; such as meanings of words, inflectional meanings, and affixal meanings), without the intervention of form representations of morphemes or whole words.

Baayen et al. (2011) show that an NDL model is able to produce the morpho-orthographic decomposition effects in Rastle et al. (2004) without a "morpho-orthographic parsing component". The model obtained significant and equal effects for transparent (employer $\rightarrow$ employ) and pseudo-derived (archer $\rightarrow$ arch) words. Because this NDL model explicitly represents form/meaning associations, it is worth reflecting on why it produces relatedness effects (interpreted as priming) between words that do not share a meaning.

Baayen et al. (2011) begin their explanation with the observation that pseudo-derived words like early, fleeting, fruitless, and archer vary in the extent to which the suffix (and sometimes the stem) conveys its regular meaning. For archer, for example, it is argued that it is still transparently related to the meaning of the suffix that marks the complex noun an agent noun, even if the base is no longer synchronically related to the complex word. The associations between the letter cues and suffix meanings then emerge because for the majority of pseudoderived items, the suffix is "fully functional in the meaning of the complex word" (Baayen et al., 2011, p. 466). Against this background, it is suggested that the equal effects for transparent and pseudo-derived items arise because the orthographic representations for suffixes have become associated with suffix meanings also in pseudo-derived items.

Part of this is clear: if words like archer are agentive nouns, and end in -er like many other transparent agent nouns like teacher do, then the 
associative learner will form an association between -er and that kind of nominal meaning. However, it remains unclear in the discussion of the NDL model why archer would have a connection with arch, which has neither the agent noun semantics, nor ends in -er. That is, learning that -er is associated with a meaning like 'agent noun' is one thing, and might associate archer with teacher; but it is not clear why (aside from string overlap) archer and arch are associated with each other in this model. $^{2}$

It is important to further note that the data modeled (from Rastle et al., 2004) are pseudo-derived. Therefore, as outlined in the Introduction, they differ in important ways from the opaque (M) condition that is employed in our paper. Subsequent models (Milin et al., 2017; Baayen et al., 2019, i.a.) change different aspects of the discriminative learner, but, crucially, these papers do not examine opaque versus transparent pairs like the ones employed in our experiments.

A recent manuscript by Baayen and Smolka (2019) does examine this for German opaque and transparent prefixed verbs, and models the German stem priming patterns using NDL. If this finding translates to Dutch, a point worth investigating in future work is why the NDL model produces this effect, if meanings are an important part of how associations are formed. It is conceivable that what the model is associating is formal strings- that is, overlapping trigram sequences. This possibility is not ruled out by the Phonological condition used in our experiment: our prefixed verbs and their stems overlap in both MS (aanbieden $\rightarrow$ bieden) and $\mathrm{M}$ (verbieden $\rightarrow$ bieden) conditions, but not in our $\mathrm{Ph}$ condition (bespieden $\rightarrow$ bieden), which was tailored to the requirements of auditory presentation (ruling out facilitation due to rhyme prime), and not directed at string overlap. One way to probe questions of this type would be to look directly at experimental evidence on the processing of string-overlapping words such as hamster $\rightarrow$ ham or homophones like bank $\rightarrow$ bank, and see how the model's behavior on these stimuli compares to prefixed verbs in our M condition.

Overall, it remains to be seen precisely what types of associations a DL model produces in our M and MS pairs. These, along with the question of how to distinguish the predictions of Full-Decomposition and learning models that produce M and MS facilitation, are important tasks for future work.

\subsection{Conclusions}

The main finding of this paper is that semantically opaque prefixed words in Dutch produce morphological priming effects. These findings have important implications for models of the mental lexicon, which can be split along the dimension of whether semantic overlap is a precondition for relatedness. These results are compatible with FullDecomposition as well as Discriminative Learning models. As noted above, further work is required to determine what might distinguish the predictions of these different models. As far as this goes, there are two further points to be made.

A first point concerns modality. There appear to be differences in morphological priming effects between visual and auditory presentation (Wilder et al., 2019), suggesting that the left-to-right nature of auditorily presented words should be taken into account in explaining the types of effects we discuss here. This is something to bear in mind in making decompositional and DL models more commensurable. For example, a DL model that predicts effects like those reported here, but which is based on orthographic representations, might be looking at something that differs in important ways from the effects that are produced in auditory processing. These differences make a direct comparison between different models difficult; along these lines, see Baayen et al. (2019) for a move towards modelling auditory comprehension.

A second point concerns the most important finding of this paper: morphological relatedness effects do not require semantic overlap. Although we have spent some time above talking about the different ways in which Full-Decomposition and Discriminative Learning models might produce this effect, the finding in itself must be emphasized. From one point of view, the fact that, despite the different starting assumptions, both Full-Decompositional and Discriminative Learning models posit that there might be relatedness effects that are independent of phonological and semantic overlap is significant. This suggests a striking point of convergence that goes beyond the different starting assumptions and explanatory aims of these approaches.

\section{Data availability}

Data and analyses are available at https://doi.org/10.17632/ c7rcjsbyhh.1.

\section{Funding}

This work was supported by the National Institutes of Health Grant No. R01HD073258.

\section{Consent}

Written informed consent was obtained for experimentation with human subjects.

\section{Declaration of Competing Interest}

None.

\section{Acknowledgements}

Many thanks are due to Hezekiah Akiva Bacovcin, Jan Don, Kobey Shwayder, the members of ExpMorph, FMART and the Language Variation and Cognition Lab at Penn, the audiences at SLE, PLC and the Mental Lexicon for their feedback, and two reviewers for their helpful comments on previous versions of this manuscript. We thank Pienie Zwitserlood for sharing her stimuli with us, and Ava Irani for proofreading the manuscript.

\section{Appendix A}

\section{A.1. Semantic relatedness pretest}

To establish the semantic relatedness between primes and targets, a semantic relatedness pre-test was conducted with at least two candidate complex verbs for every target base verb. For both experiments, twelve native speakers of Dutch were asked to rate the semantic relatedness of word pairs on a seven-point scale, with 1 being 'completely unrelated in meaning' and 7 being 'highly related in meaning'. The pretest was conducted through Qualtrics. For every target, multiple primes were included in the pretest, so that the semantically most/least related pairs could be selected as critical items. Targets for which it turned out that there was no appropriate prime in one or more of the conditions were excluded.

\footnotetext{
${ }^{2}$ Another question for the Baayen et al. (2011) model concerns what precisely is being modelled. The contrast between the results in masked versus overt priming

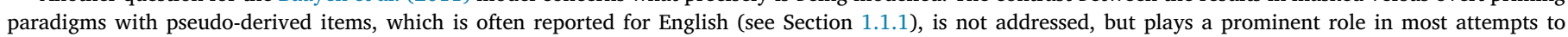
understand these phenomena.
} 
Criteria for including items as critical items in Experiment 1 were as follows: MS verbs needed to have a mean semantic score that was higher than 4, and $\mathrm{M}, \mathrm{Ph}$, and $\mathrm{C}$ verbs needed to have a mean score lower than 3 in order to be included in the critical items. This resulted in the 36 critical item stems (targets) and their complex verbs (primes) in the four different conditions that were used in this experiment. A one-way ANOVA was performed on mean semantic scores, which showed highly significant differences between conditions $(\mathrm{F}(3,140)=698.7, p<0.001)$. Post-hoc testing with Tukey's test shows that the MS and M conditions are significantly different $(p<0.001)$.

For Experiment 2, criteria for inclusion were identical to those for Experiment 1. In addition, $S$ primes needed to have a mean semantic score that is higher than 4 (similar to MS primes). A one-way ANOVA was performed on mean semantic scores, which showed highly significant differences between conditions $(\mathrm{F}(3,156)=652.1, p<0.001)$. Post-hoc testing with Tukey's test shows that the MS and $\mathrm{S}$ conditions do not significantly differ $(p$ $=0.876)$, while the semantic scores in the MS and M conditions are significantly different $(p<0.001)$.

\section{Appendix B}

\section{B.1. Stimuli Experiment 1}

See Table 9

Table 9

Stimuli in Experiment 1, for the target (the stem + infinitival suffix) and the primes in the Morphologically and Semantically related (MS), only Morphologically related (M), Phonologically related (Ph), and Control (C) conditions. For Ph prime-target pairs, the stem of the prime and the target rhyme: they only differ in their onset consonant or consonant cluster, while sharing the rhyme. In two cases (houden and nemen) we allowed a minimal difference in the coda as well, since no rhyming alternative could be found.

\begin{tabular}{|c|c|c|c|c|}
\hline Target & MS prime & M prime & $\mathrm{Ph}$ prime & $\mathrm{C}$ prime \\
\hline bieden & aanbieden & verbieden & bespieden & opjagen \\
\hline 'offer' & ‘offer' & 'forbid' & 'spie on' & 'rush' \\
\hline bijten & afbijten & verbijten & verwijten & verhuren \\
\hline 'bite' & 'bite off' & 'suppress' & 'blame' & 'lease' \\
\hline blijven & verblijven & afblijven & verdrijven & opmeten \\
\hline 'stay’ & ‘stay’ & 'keep off' & ‘expel’' & 'measure' \\
\hline breken & afbreken & aanbreken & afspreken & beklimmen \\
\hline 'break' & 'break off' & 'open, begin' & 'arrange' & 'climb’ \\
\hline brengen & wegbrengen & volbrengen & verlengen & opdrogen \\
\hline 'bring' & 'deliver' & 'accomplish' & 'extend' & 'dry up' \\
\hline dekken & bedekken & ontdekken & uitlekken & uitkiezen \\
\hline ‘cover’ & 'cover' & 'discover' & 'leak' & 'select' \\
\hline denken & nadenken & verdenken & inschenken & verbranden \\
\hline 'think' & 'think' & 'suspect' & 'pour’ & 'burn' \\
\hline dragen & meedragen & opdragen & aanklagen & verbranden \\
\hline 'carry' & ‘carry' & 'commission' & 'sue' & 'burn' \\
\hline drinken & opdrinken & verdrinken & bezinken & instoppen \\
\hline ‘drink’ & 'drink up' & 'drown' & 'sink' & 'put in' \\
\hline geven & aangeven & begeven & inleven & opblazen \\
\hline 'give' & 'hand' & 'break down' & 'empathize' & 'blow' \\
\hline grijpen & vastgrijpen & begrijpen & uitknijpen & uitlachen \\
\hline 'grab' & 'grasp' & 'understand' & 'squeeze out' & 'ridicule' \\
\hline halen & afhalen & herhalen & afdwalen & uitpluizen \\
\hline 'take, get' & 'pick up' & 'repeat' & 'stray off' & 'unravel' \\
\hline hangen & ophangen & afhangen & ontvangen & verschuilen \\
\hline 'hang' & 'hang' & 'depend on' & 'receive' & 'hide' \\
\hline houden & behouden & ophouden & aanschouwen & vermijden \\
\hline 'keep' & 'retain' & 'stop’ & 'see' & ‘avoid' \\
\hline kennen & herkennen & bekennen & wegrennen & afscheiden \\
\hline 'know' & 'recognize' & 'confess' & 'run away' & 'secrete' \\
\hline kijken & bekijken & verkijken & ontwijken & opvragen \\
\hline 'look' & 'see' & 'make a mistake' & 'avoid' & 'request' \\
\hline kopen & inkopen & bekopen & ontknopen & opduiken \\
\hline ‘buy' & 'buy’' & 'pay dearly' & 'solve' & ‘surface’ \\
\hline krijgen & verkrijgen & afkrijgen & opstijgen & ontvoeren \\
\hline 'get' & 'obtain’ & 'complete' & 'ascend' & 'kidnap' \\
\hline lopen & doorlopen & verlopen & omdopen & bewaken \\
\hline 'walk' & 'walk, hurry' & 'expire' & 'rename' & 'guard' \\
\hline maken & aanmaken & uitmaken & afkraken & aanvoelen \\
\hline 'make' & 'prepare' & $\begin{array}{l}\text { 'extinguish, } \\
\text { break up' }\end{array}$ & 'run down' & 'sense' \\
\hline nemen & aannemen & vernemen & verlenen & opvouwen \\
\hline 'take' & 'take' & 'find out' & 'give, grant' & 'fold up' \\
\hline rotten & verrotten & oprotten & bespotten & aanspannen \\
\hline 'rot' & ‘decay’ & 'piss off' & 'ridicule' & 'rig, yoke' \\
\hline schieten & beschieten & opschieten & begieten & bezoeken \\
\hline 'shoot' & 'fire on/at' & 'hurry up' & 'pour over' & 'visit' \\
\hline schrijven & opschrijven & toeschrijven & inwrijven & opeten \\
\hline 'write' & 'write up' & 'attribute' & 'rub in(to)' & 'eat' \\
\hline sluiten & afsluiten & besluiten & uitbuiten & verschijnen \\
\hline
\end{tabular}


Table 9 (continued)

\begin{tabular}{|c|c|c|c|c|}
\hline Target & MS prime & M prime & $\mathrm{Ph}$ prime & C prime \\
\hline 'close' & 'close' & 'choose, decide' & 'exploit' & 'appear' \\
\hline steken & neersteken & afsteken & inweken & omfietsen \\
\hline ‘stab’ & 'stick out' & 'let off' & 'soak' & 'cycle round' \\
\hline tikken & aantikken & vertikken & aandikken & vervloeken \\
\hline 'tap' & 'tap' & 'refuse' & 'embroider' & 'curse' \\
\hline trappen & vertrappen & betrappen & aanpappen & opwachten \\
\hline 'kick' & 'trample' & 'catch s/o' & 'chum up' & 'wait for s/o' \\
\hline trekken & optrekken & vertrekken & uitstrekken & verslapen \\
\hline 'pull' & 'pull up' & 'leave’ & 'stretch (out)' & 'oversleep' \\
\hline vallen & omvallen & bevallen & uitstallen & bijkomen \\
\hline 'fall' & 'topple' & $\begin{array}{l}\text { 'give birth, } \\
\text { satisfy' }\end{array}$ & ‘display’ & 'recover' \\
\hline wegen & afwegen & bewegen & verplegen & opbellen \\
\hline 'weigh' & 'weigh' & 'move' & 'nurse' & ‘call up' \\
\hline wennen & aanwennen & verwennen & afremmen & bezweren \\
\hline 'get used to' & 'get used to' & 'pamper' & $\begin{array}{l}\text { 'slow down, } \\
\text { brake' }\end{array}$ & ‘swear’ \\
\hline werpen & afwerpen & ontwerpen & aanscherpen & uitdraaien \\
\hline 'throw' & 'throw off' & ‘design’ & 'sharpen' & 'print out' \\
\hline wijzen & aanwijzen & bewijzen & vergrijzen & uitgraven \\
\hline 'point' & 'point out' & 'prove' & 'age, get old' & 'excavate' \\
\hline wonen & bewonen & bijwonen & bekronen & verslijten \\
\hline 'live' & 'inhabit' & 'attend' & 'award' & 'wear out' \\
\hline zetten & neerzetten & bezetten & invetten & besproeien \\
\hline 'put' & 'put down' & ‘occupy’ & 'grease' & 'sprinkle' \\
\hline
\end{tabular}

\section{Appendix C}

\section{C.1. Stimuli Experiment 2}

See Table 10

Table 10

Stimuli in Experiment 2, for the target (i.e., the stem + infinitival morpheme) and the primes in the Morphologically and Semantically related (MS), only Morphologically related (M), Semantically related (S), and Control (C) conditions. Stimuli other than the S primes which were not included in Experiment 1 are indicated with an asterisk.

\begin{tabular}{|c|c|c|c|c|}
\hline Target & MS prime & M prime & S prime & $\mathrm{C}$ prime \\
\hline bieden & aanbieden & verbieden & verlenen & opjagen \\
\hline 'offer' & 'offer' & 'forbid' & 'give, grant' & 'rush' \\
\hline bijten & afbijten & verbijten & toehappen & verhuren \\
\hline 'bite' & 'bite off' & 'suppress' & 'snap, bite' & 'lease' \\
\hline blijven & verblijven & afblijven & voortduren & opmeten \\
\hline ‘stay’ & 'stay' & 'keep off' & 'persist' & 'measure' \\
\hline breken & afbreken & aanbreken & vernielen & beklimmen \\
\hline 'break' & 'break off' & 'open, begin' & 'wreck, ruin' & 'climb’ \\
\hline brengen & wegbrengen & volbrengen & bezorgen & opdrogen \\
\hline 'bring' & 'deliver' & 'accomplish' & 'deliver' & 'dry up' \\
\hline dekken & bedekken & ontdekken & afschermen & uitkiezen \\
\hline 'cover' & 'cover' & 'discover' & 'shield, cover' & 'select' \\
\hline denken & nadenken & verdenken & beraden & verscheuren \\
\hline 'think' & 'think' & 'suspect' & 'consider' & 'tear, rip' \\
\hline dragen & meedragen & opdragen & meetorsen & verbranden \\
\hline 'carry' & 'carry' & 'commission' & ‘carry along' & 'burn' \\
\hline drinken & opdrinken & verdrinken & opslorpen & instoppen \\
\hline 'drink' & 'drink up' & 'drown' & 'sip, absorb' & 'put in' \\
\hline geven & aangeven & begeven & verstrekken & opblazen \\
\hline 'give' & 'hand' & 'break down' & 'supply with' & 'blow' \\
\hline grijpen & vastgrijpen & begrijpen & vastpakken & uitlachen \\
\hline 'grab' & 'grasp' & 'understand' & 'grab' & 'ridicule' \\
\hline halen & afhalen & herhalen & bereiken & uitpluizen \\
\hline 'take, get' & 'pick up' & 'repeat' & 'reach' & 'unravel' \\
\hline hangen & ophangen & afhangen & vastkleven & verschuilen \\
\hline
\end{tabular}


Table 10 (continued)

\begin{tabular}{|c|c|c|c|c|}
\hline Target & MS prime & M prime & S prime & C prime \\
\hline 'hang' & 'hang' & 'depend on' & 'stick’ & 'hide' \\
\hline houden & behouden & ophouden & bewaren & vermijden \\
\hline 'keep’ & 'retain' & ‘stop’ & 'keep' & ‘avoid’ \\
\hline kennen & herkennen & bekennen & beheersen & afscheiden \\
\hline 'know' & 'recognize' & 'confess' & $\begin{array}{l}\text { 'have } \\
\text { command of' }\end{array}$ & 'secrete' \\
\hline keren* & omkeren* & uitkeren* & omdraaien & omlijnen* \\
\hline 'turn' & 'turn back' & 'pay (out)' & 'turn (round)' & 'delineate' \\
\hline kijken & bekijken & verkijken & aanschouwen & opvragen \\
\hline 'look' & 'see' & 'make a mistake' & 'see' & 'request' \\
\hline komen* & meekomen* & omkomen* & verschijnen & vergissen* \\
\hline 'come' & 'come (along)' & 'die' & 'appear' & 'mistake' \\
\hline kopen & inkopen & bekopen & aanschaffen & opduiken \\
\hline ‘buy’ & 'buy’' & 'pay dearly' & $\begin{array}{l}\text { 'procure, } \\
\text { purchase' }\end{array}$ & 'pop up' \\
\hline krijgen & verkrijgen & afkrijgen & ontvangen & ontvoeren \\
\hline 'get' & 'obtain' & 'complete' & 'receive' & 'kidnap' \\
\hline lopen & doorlopen & verlopen & bewandelen & bewaken \\
\hline 'walk' & 'walk, hurry' & 'expire’ & ‘walk (on)’ & 'guard' \\
\hline maken & aanmaken & uitmaken & verstellen & aanvoelen \\
\hline 'make' & 'prepare' & $\begin{array}{l}\text { 'extinguish, } \\
\text { break up' }\end{array}$ & 'repair' & 'sense' \\
\hline nemen & meenemen* & vernemen & gebruiken & opvouwen \\
\hline 'take' & 'take with' & 'find out' & 'take to use' & 'fold up' \\
\hline roeren* & omroeren* & ontroeren* & vermengen & aankleden* \\
\hline ‘stir' & 'stir' & 'touch, move' & 'mix' & 'get dressed' \\
\hline rotten & verrotten & oprotten & bederven & aanspannen \\
\hline 'rot' & ‘decay’ & 'piss off' & ‘decay, spoil’ & 'rig, yoke' \\
\hline schieten & beschieten & opschieten & afvuren & bezoeken \\
\hline 'shoot' & 'fire on/at' & $\begin{array}{l}\text { 'hurry up, push } \\
\text { on' }\end{array}$ & 'fire' & 'visit' \\
\hline schrijven & opschrijven & toeschrijven & berichten & opeten \\
\hline 'write' & 'write up' & 'attribute' & 'send word' & 'eat' \\
\hline sluiten & afsluiten & besluiten & opheffen & vermalen* \\
\hline 'close' & 'close' & 'choose, decide' & 'discontinue' & 'grind' \\
\hline spreken* & toespreken* & afspreken* & vertellen & aanrijden* \\
\hline 'speak' & 'speak to' & $\begin{array}{l}\text { 'agree (on), } \\
\text { arrange' }\end{array}$ & 'tell' & 'run down' \\
\hline steken & neersteken & afsteken & inprikken & omfietsen \\
\hline 'stab' & 'stick out' & 'let off' & 'prick' & 'cycle round' \\
\hline tikken & aantikken & vertikken & bekloppen & vervloeken \\
\hline 'tap' & 'tap' & 'refuse' & 'tap' & ‘curse' \\
\hline trappen & vertrappen & betrappen & wegschoppen & opwachten \\
\hline 'kick' & 'trample' & 'catch s/o' & 'kick away' & 'wait for s/o' \\
\hline trekken & optrekken & vertrekken & ophijsen & verslapen \\
\hline ‘pull’ & 'pull up' & 'leave' & 'raise' & 'oversleep' \\
\hline vallen & omvallen & bevallen & neerstorten & uitdagen* \\
\hline 'fall' & 'topple' & $\begin{array}{l}\text { 'give birth, } \\
\text { satisfy' }\end{array}$ & ‘crash’ & 'challenge' \\
\hline wegen & afwegen & bewegen & bepalen & opbellen \\
\hline 'weigh' & 'weigh' & 'move' & 'determine' & ‘call up’ \\
\hline wennen & aanwennen & verwennen & aanpassen & bezweren \\
\hline 'get used to' & 'get used to' & 'pamper' & 'adapt to' & 'swear' \\
\hline werpen & afwerpen & ontwerpen & weggooien & verbuigen* \\
\hline 'throw' & 'throw off' & ‘design' & 'throw away' & 'bend' \\
\hline wijzen & aanwijzen & bewijzen & aanduiden & uitgraven \\
\hline 'point' & 'point out' & 'prove' & 'indicate' & 'excavate' \\
\hline wonen & bewonen & bijwonen & vertoeven & verslijten \\
\hline 'live' & 'inhabit' & 'attend' & ‘stay’ & 'wear out' \\
\hline zetten & neerzetten & bezetten & verplaatsen & besproeien \\
\hline 'put' & 'put down' & 'occupy' & $\begin{array}{l}\text { 'move, } \\
\text { relocate' }\end{array}$ & 'sprinkle' \\
\hline
\end{tabular}




\section{Appendix D}

D.1. Additional Linear Mixed Effects Model, Experiment 1

See Table 11

Table 11

LME Model summary for the analysis of RT data in Experiment 1, with the reference level of PRIMECONDITION set to the M condition. ${ }^{\text {a }}$

\begin{tabular}{|c|c|c|c|}
\hline \multirow[b]{2}{*}{ Fixed Effects } & \multicolumn{3}{|c|}{ Log-transformed RT } \\
\hline & Estimate $(\beta)$ & t-value & p-value \\
\hline (Intercept) & 6.71 & 404.283 & $<.001$ \\
\hline \multicolumn{4}{|l|}{ Prime Condition (M) } \\
\hline C & 0.10 & 8.150 & $<.001$ \\
\hline MS & -0.02 & -1.377 & .169 \\
\hline$P h$ & 0.08 & 6.378 & $<.001$ \\
\hline Prime Prefix & 0.02 & 2.634 & .008 \\
\hline Trial Number & -0.04 & -9.543 & $<.001$ \\
\hline ISI & 0.00 & 0.159 & .874 \\
\hline Target Frequency & -0.02 & -2.631 & .009 \\
\hline Prime Frequency & 0.02 & 3.515 & $<.001$ \\
\hline Target Neighborhood Density & -0.01 & -1.272 & .203 \\
\hline Target Duration & 0.07 & 9.831 & $<.001$ \\
\hline Prime RT (log) & 0.05 & 11.041 & $<.001$ \\
\hline Random Effects & $N$ & Variance & St. dev \\
\hline Primes & 143 & 0.0003 & 0.018 \\
\hline Targets & 36 & 0.0009 & 0.030 \\
\hline Subjects & 32 & 0.0057 & 0.076 \\
\hline Residual & & 0.0157 & 0.126 \\
\hline N Datapoints & 1055 & & \\
\hline
\end{tabular}

${ }^{\text {a }}$ Significant $p$-values $(p<0.05)$ are shown bold faced.

\section{Appendix E}

\section{E.1. Additional Linear Mixed Effects Models, Experiment 2}

See Tables 12 and 13

Table 12

Linear Mixed Effects Model for analysis of Experiment 2, with the reference level of PRIMECondrimon set to the MS condition, and the reference level of DISTANCE set to 0-lag. ${ }^{\text {a }}$

\begin{tabular}{|c|c|c|c|}
\hline \multirow[b]{2}{*}{ Fixed Effects } & \multicolumn{3}{|c|}{ Log-transformed RT } \\
\hline & Estimate $(\beta)$ & $t$-value & $p$-value \\
\hline (Intercept) & 6.80 & 320.784 & $<.001$ \\
\hline \multicolumn{4}{|l|}{ Prime Condition (MS) } \\
\hline C & 0.06 & 3.848 & $<.001$ \\
\hline$M$ & -0.01 & -0.375 & .708 \\
\hline$S$ & 0.04 & 3.065 & .002 \\
\hline Distance 5-lag & 0.07 & 5.356 & $<.001$ \\
\hline Prime Prefix & 0.00 & 0.199 & .842 \\
\hline Trial Number & -0.02 & -3.165 & .002 \\
\hline ISI & 0.00 & 0.560 & .576 \\
\hline Target Frequency & -0.01 & -1.910 & .056 \\
\hline Prime Frequency & 0.00 & 1.111 & .267 \\
\hline Target Neighborhood Density & -0.01 & -1.948 & .051 \\
\hline Target Duration & 0.06 & 9.016 & $<.001$ \\
\hline Prime Condition C: Distance 5-lag & -0.06 & -3.627 & $<.001$ \\
\hline Prime Condition M: Distance 5-lag & -0.01 & -0.529 & .597 \\
\hline Prime Condition S: Distance 5-lag & -0.04 & -2.194 & .028 \\
\hline Random Effects & $N$ & Variance & St. dev \\
\hline Prime Intercept & 160 & 0.0000 & 0.000 \\
\hline
\end{tabular}


Table 12 (continued)

\begin{tabular}{lccc}
\hline & & Log-transformed RT \\
\hline Targets & 40 & 0.0016 & 0.040 \\
Intercept & & 0.0021 & 0.046 \\
MS slope & 40 & 0.0095 & 0.098 \\
Subjects & & 0.0003 & 0.016 \\
Intercept & & 0.0137 & 0.117 \\
MS slope & 1425 & & \\
Residual & & & \\
N Datapoints & & & \\
\hline
\end{tabular}

a Significant $p$-values $(p<0.05)$ are shown bold faced.

Table 13

Linear Mixed Effects Model for analysis of Experiment 2, with the reference level of PRIMECondriton set to the C condition, and the reference level of DISTANCE set to 5-lag. ${ }^{a}$

\begin{tabular}{|c|c|c|c|}
\hline \multirow[b]{2}{*}{ Fixed Effects } & \multicolumn{3}{|c|}{ Log-transformed RT } \\
\hline & Estimate $(\beta)$ & t-value & $p$-value \\
\hline (Intercept) & 6.86 & 362.828 & $<.001$ \\
\hline \multicolumn{4}{|l|}{ Prime Condition (C) } \\
\hline MS & 0.01 & 0.507 & 612 \\
\hline$M$ & -0.01 & -0.561 & .575 \\
\hline$s$ & 0.01 & 1.094 & .274 \\
\hline Distance 0-lag & -0.00 & -0.188 & .851 \\
\hline Prime Prefix & 0.00 & 0.199 & .842 \\
\hline Trial Number & -0.02 & -3.165 & .002 \\
\hline ISI & 0.00 & 0.560 & .576 \\
\hline Target Frequency & -0.01 & -1.910 & .056 \\
\hline Prime Frequency & 0.00 & 1.111 & .267 \\
\hline Target Neighborhood Density & -0.01 & -1.948 & .051 \\
\hline Target Duration & 0.06 & 9.016 & $<.001$ \\
\hline Prime Condition MS: Distance 0-lag & -0.06 & -3.627 & $<.001$ \\
\hline Prime Condition M: Distance 0-lag & -0.05 & -3.100 & .002 \\
\hline Prime Condition S: Distance 0-lag & -0.03 & -1.419 & 156 \\
\hline Random Effects & $N$ & Variance & St. dev \\
\hline Prime Intercept & 160 & 0.0000 & 0.000 \\
\hline Targets & 40 & & \\
\hline Intercept & & 0.0016 & 0.040 \\
\hline MS slope & & 0.0021 & 0.046 \\
\hline Subjects & 40 & & \\
\hline Intercept & & 0.0095 & 0.098 \\
\hline MS slope & & 0.0003 & 0.016 \\
\hline Residual & & 0.0137 & 0.117 \\
\hline N Datapoints & 1425 & & \\
\hline
\end{tabular}

a Significant $p$-values $(p<0.05)$ are shown bold faced.

\section{References}

Amenta, S., \& Crepaldi, D. (2012). Morphological processing as we know it: An analytical review of morphological effects in visual word identification. Frontiers in Psychology, 3 Article 232.

Andrews, S., \& Lo, S. (2013). Is morphological priming stronger for transparent than opaque words? It depends on individual differences in spelling and vocabulary. Journal of Memory and Language, 68, 279-296. https://doi.org/10.1016/j.jml.2012. 12.001.

Anglin, J. M. (1993). Vocabulary development: A morphological analysis. Monographs of the Society of Research in Child Development, 58, 1-166.

Aronoff, M. (1976). Word formation in generative grammar. Cambridge, Mass.: Linguistic Inquiry Monographs.

Baayen, R. H. \& Smolka, E. (2019).Modeling morphological priming in German with naïve discriminative learning. PsyArXiv, preprint doi:https://doi.org/10.31234/osf.io/nj39v.

Baayen, R. H., Chuang, Y., Shafaei-Bajestan, E., \& Blevins, J. P. (2019). The discriminative lexicon: A unified computational model for the lexicon and lexical processing in comprehension and production grounded not in (de) composition but in linear discriminative learning. Complexity, 1-39 Article ID 4895891.

Baayen, R. H., Dijkstra, T., \& Schreuder, R. (1997). Singulars and plurals in Dutch: Evidence for a parallel dual-route model. Journal of Memory and Language, 37, 94-117.

Baayen, R.H., Bates, D., Kliegl, R., \& Vasishth, S. (2015). RePsychLing: Data sets from
Psychology and Linguistics experiments. R package version 0.0.4.

Baayen, R. H., \& Milin, P. (2010). Analyzing reaction times. International Journal of Psychological Research, 3, 12-28.

Baayen, R. H., Milin, P., Đurđević, D. F., Hendrix, P., \& Marelli, M. (2011). An amorphous model for morphological processing in visual comprehension based on naive discriminative learning. Psychological Review, 118, 438-481.

Bacovcin, H. A., Goodwin Davies, A., Wilder, R. J., \& Embick, D. (2017). Auditory morphological processing: Evidence from phonological priming. Cognition, 164, 102-106.

Balling, L. W., \& Baayen, R. H. (2008). Morphological effects in auditory word recognition: Evidence from Danish. Language and Cognitive Processes, 23, 1159-1190.

Balling, L. W., \& Baayen, R. H. (2012). Probability and surprisal in auditory comprehension of morphologically complex words. Cognition, 125, 80-106.

Bates, D., Kliegl, R., Vasishth, S., \& Baayen, R. H. (2015a). Parsimonious mixed models, arXiv preprint arXiv:1506.04967.

Bates, D., Mächler, M., Bolker, B., \& Walker, S. (2015). Fitting linear mixed-effects models using lme4. Journal of Statistical Software, 67, 1-48. https://doi.org/10.18637/jss. v067.i01.

Bentin, S., \& Feldman, L. B. (1990). The contribution of morphological and semantic relatedness to repetition priming at short and long lags: Evidence from Hebrew. The Quarterly Journal of Experimental Psychology, 42, 693-711.

Bertram, R. (2011). Eye movements and morphological processing in reading. The Mental Lexicon, 6, 83-109. 
Bertram, R., Laine, M., Baayen, R. H., Schreuder, R., \& Hyönä, J. (2000). Affixal homonymy triggers full-form storage, even with inflected words, even in a morphologically rich language. Cognition, 74, B13-B25.

Beyersmann, E., Ziegler, J. C., Castles, A., Coltheart, M., Kezilas, Y., \& Grainger, J. (2016). Morpho-orthographic segmentation without semantics. Psychonomic Bulletin \& Review, 23, 533-539.

Boersma, P. \& Weenink, D. (2015). Praat: Doing phonetics by computer. Version 6.0. 05 Boudelaa, S., \& Marslen-Wilson, W. D. (2004). Abstract morphemes and lexical representation: The CV-skeleton in Arabic. Cognition, 92, 271-303.

Boudelaa, S., \& Marslen-Wilson, W. D. (2005). Discontinuous morphology in time: Incremental masked priming in Arabic. Language and Cognitive Processes, 20, 207-260.

Boudelaa, S., \& Marslen-Wilson, W. D. (2015). Structure, form, and meaning in the mental lexicon: Evidence from Arabic. Language, Cognition and Neuroscience, 30, 955-992.

Burani, C., \& Caramazza, A. (1987). Representation and processing of derived words. Language and Cognitive Processes, 2, 217-227.

Burani, C., \& Laudanna, A. (1992). Units of representation for derived words in the lexicon. Advances in psychology: Vol. 94, (pp. 361-376). Elsevier.

Caramazza, A., Laudanna, A., \& Romani, C. (1988). Lexical access and inflectional morphology. Cognition, 28, 297-332.

Carstairs-McCarthy, A. (1992). Current morphology. London: Routledge.

Goodwin Davies, A. \& Embick, D. (2019). The representation of plural inflectional affixes in English: Evidence from priming in an auditory lexical decision task. submitted for publication.

De Grauwe, S., Lemhöfer, K., \& Schriefers, H. (2019). Processing derived verbs: The role of motor-relatedness and type of morphological priming. Language, Cognition and Neuroscience, 34(8), 973-999.

Den Besten, H. (1983/89). On the interaction of root transformations and lexical deletive rules. In: Werner Abrahams (ed.), On the formal syntax of the Westgermania (pp. 47-131). Reprinted in Hans den Besten. (1989). Studies in Westgermanic syntax. Doctoral dissertation, Katholieke Universiteit Brabant. Amsterdam + Atlanta, GA: Rodopi. ())

Derwing, B. L., \& Baker, W. J. (1986). Assessing morphological development. Language Acquisition: Studies in First Language Development, 2, 326-338.

Diependaele, K., Sandra, D., \& Grainger, J. (2005). Masked cross-modal morphological priming: Unravelling morpho-orthographic and morpho-semantic influences in early word recognition. Language and Cognitive Processes, 20, 75-114.

Diependaele, K., Sandra, D., \& Grainger, J. (2009). Semantic transparency and masked morphological priming: The case of prefixed words. Memory \& Cognition, 37, 895-908.

Duncan, L. G., Casalis, S., \& Colé, P. (2009). Early metalinguistic awareness of derivational morphology: Observations from a comparison of English and French. Applied Psycholinguistics, 30, 405-440.

Embick, D. (2015). The morpheme: A theoretical introduction, Vol. 31. Walter de Gruyter $\mathrm{GmbH} \& \mathrm{Co} \mathrm{KG}$.

Feldman, L. B. (2000). Are morphological effects distinguishable from the effects of shared meaning and shared form? Journal of Experimental Psychology-Learning Memory and Cognition, 26, 1431-1444.

Feldman, L. B., Barac-Cikoja, D., \& Kostić, A. (2002). Semantic aspects of morphological processing: Transparency effects in Serbian. Memory \& Cognition, 30, 629-636.

Feldman, L. B., \& Bentin, S. (1994). Morphological analysis of disrupted morphemes: Evidence from Hebrew. The Quarterly Journal of Experimental Psychology, 47, 407-435.

Feldman, L. B., Milin, P., Cho, K. W., del Prado, Moscoso, Martín, F., \& O’Connor, P. A. (2015). Must analysis of meaning follow analysis of form? A time course analysis. Frontiers in Human Neuroscience, 9, 111. https://doi.org/10.3389/fnhum.2015. 00111.

Feldman, L. B., O'Connor, P. A., \& del Prado Martín, F. M. (2009). Early morphological processing is morpho-semantic and not simply morpho-orthographic: A violation of form-then-meaning accounts of word recognition. Psychonomic Bulletin \& Review, 16, 684-691.

Feldman, L. B., Soltano, E., Pastizzo, M., \& Francis, S. (2004). What do graded effects of semantic transparency reveal about morphological processing? Brain and Language, $90,17-30$.

Fiorentino, R., \& Poeppel, D. (2007). Compound words and structure in the lexicon. Language and Cognitive Processes, 22, 953-1000.

Forster, K. I., Davis, C., Schoknecht, C., \& Carter, R. (1987). Masked priming with graphemically related forms: Repetition or partial activation? The Quarterly Journal of Experimental Psychology Section A, 39, 211-251.

Frauenfelder, U. H., \& Schreuder, R. (1992). Constraining psycholinguistic models of morphological processing and representation: The role of productivity. Yearbook of morphology 1991 (pp. 165-183). Springer.

Frost, R., Deutsch, A., Gilboa, O., Tannenbaum, M., \& Marslen-Wilson, W. D. (2000), Morphological priming: Dissociation of phonological, semantic, and morphological factors. Memory \& Cognition, 28, 1277-1288.

Frost, R., Forster, K. I., \& Deutsch, A. (1997). What can we learn from the morphology of Hebrew? A masked-priming investigation of morphological representation. Journal of Experimental Psychology: Learning, Memory, and Cognition, 23, 829-856.

Fruchter, J., \& Marantz, A. (2015). Decomposition, lookup, and recombination: MEG evidence for the full decomposition model of complex visual word recognition. Brain and Language, 143, 81-96.

Giraudo, H., \& Grainger, J. (2001). Priming complex words: Evidence for supralexical representation of morphology. Psychonomic Bulletin \& Review, 8, 127-131.

Giraudo, H., \& Grainger, J. (2003). A supralexical model for French derivational morphology. Reading complex words (pp. 139-157). Springer.

Gonnerman, L. M., Seidenberg, M. S., \& Andersen, E. S. (2007). Graded semantic and phonological similarity effects in priming: Evidence for a distributed connectionist approach to morphology. Journal of Experimental Psychology: General, 136, 323-345.

Goodwin Davies, A. J. (2018). Morphological representations in lexical processing. Ph.D. thesisUniversity of Pennsylvania.
Hall, K. C., Allen, C., Fairburn, T., Fry, M., McAuliffe, M., \& McMullin, K. (2016). Measuring perceived morphological relatedness. Canadian Journal of Linguistics/Revue canadienne de linguistique, 61, 31-67.

Hanique, I., Aalders, E., \& Ernestus, M. (2013). How robust are exemplar effects in word comprehension? The Mental Lexicon, 8, 269-294.

Keuleers, E., Brysbaert, M., \& New, B. (2010). SUBTLEX-NL: A new measure for Dutch word frequency based on film subtitles. Behavior Research Methods, 42, 643-650.

Kouider, S., \& Dupoux, E. (2009). Episodic accessibility and morphological processing: Evidence from long-term auditory priming. Acta Psychologica, 130, 38-47.

Kuperman, V., Bertram, R., \& Baayen, R. H. (2010). Processing trade-offs in the reading of Dutch derived words. Journal of Memory and Language, 62, 83-97.

Kuperman, V., Schreuder, R., Bertram, R., \& Baayen, R. H. (2009). Reading polymorphemic Dutch compounds: Toward a multiple route model of lexical processing. Journal of Experimental Psychology: Human Perception and Performance, 35, 876-895.

Kuznetsova, A., Brockhoff, P. B., \& Christensen, R. H. B. (2016). lmerTest: Tests in linear mixed effects models. $\mathrm{R}$ package version 2.0-32.

Lavric, A., Elchlepp, H., \& Rastle, K. (2012). Tracking hierarchical processing in morphological decomposition with brain potentials. Journal of Experimental Psychology: Human Perception and Performance, 38, 811-816.

Lavric, A., Rastle, K., \& Clapp, A. (2011). What do fully visible primes and brain potentials reveal about morphological decomposition? Psychophysiology, 48, 676-686.

Lieber, R., \& Baayen, R. H. (1993). Verbal prefixes in Dutch: A study in lexical conceptual structure. Yearbook of morphology 1993 (pp. 51-78). Springer.

Longtin, C. M., Segui, J., \& Halle, P. (2003). Morphological priming without morphological relationship. Language and Cognitive Processes, 18, 313-334.

Mahony, D., Singson, M., \& Mann, V. (2000). Reading ability and sensitivity to morphological relations. Reading and Writing, 12, 191-218.

Marantz, A. (2013). No escape from morphemes in morphological processing. Language and Cognitive Processes, 28, 905-916.

Marian, V., Bartolotti, J., Chabal, S., \& Shook, A. (2012). CLEARPOND: Cross-linguistic easy-access resource for phonological and orthographic neighborhood densities. PloS One, 7, e43230.

Marslen-Wilson, W. D. (1984). Function and process in spoken word recognition: A tutorial review. Attention and performance: Control of language processes (pp. 125-150). Hove, UK: Lawrence Erlbaum Associates.

Marslen-Wilson, W. D., Bozic, M., \& Randall, B. (2008). Early decomposition in visual word recognition: Dissociating morphology, form, and meaning. Language and Cognitive Processes, 23, 394-421.

Marslen-Wilson, W. D., \& Tyler, L. K. (1998). Rules, representations, and the English past tense. Trends in Cognitive Sciences, 2, 428-435.

Marslen-Wilson, W. D., Tyler, L. K., Waksler, R., \& Older, L. (1994). Morphology and meaning in the English mental lexicon. Psychological Review, 101, 3-33.

Mattingly, I. G. (1984). Reading, linguistic awareness, and language acquisition. Language awareness and learning to read (pp. 9-25). Springer.

McCormick, S. F., Rastle, K., \& Davis, M. H. (2008). Is there a 'fete' in 'fetish'? Effects of orthographic opacity on morpho-orthographic segmentation in visual word recognition. Journal of Memory and Language, 58, 307-326.

Milin, P., Feldman, L. B., Ramscar, M., Hendrix, P., \& Baayen, R. H. (2017). Discrimination in lexical decision. PloS One, 12, e0171935.

Norris, D., McQueen, J. M., \& Cutler, A. (2002). Bias effects in facilitatory phonological priming. Memory \& Cognition, 30, 399-411.

Peirce, J. W. (2007). Psychopy-psychophysics software in python. Journal of Neuroscience Methods, 162, 8-13.

Plaut, D. C., \& Gonnerman, L. M. (2000). Are non-semantic morphological effects incompatible with a distributed connectionist approach to lexical processing? Language and Cognitive Processes, 15, 445-485.

Rastle, K., \& Davis, M. H. (2003). Reading morphologically complex words. Masked priming: The state of the art (pp. 279-305).

Rastle, K., \& Davis, M. (2008). Morphological decomposition based on the analysis of orthography. Language and Cognitive Processes, 23, 942-971.

Rastle, K., Davis, M., Marslen-Wilson, W. D., \& Tyler, L. (2000). Morphological and semantic effects in visual word recognition: A time-course study. Language and Cognitive Processes, 15, 507-537.

Rastle, K., Davis, M., \& New, B. (2004). The broth in my brother's brothel: Morphoorthographic segmentation in visual word recognition. Psychonomic Bulletin \& Review, 11, 1090-1098.

Raveh, M. (2002). The contribution of frequency and semantic similarity to morphological processing. Brain and Language, 81, 312-325.

$\mathrm{R}$ Core Team (2016). R: A language and environment for statistical computing. Austria: $\mathrm{R}$ Foundation for Statistical Computing Vienna. https://www.R-project.org/.

Schmidtke, D., Matsuki, K., \& Kuperman, V. (2017). Surviving blind decomposition: A distributional analysis of the time-course of complex word recognition. Journal of Experimental Psychology: Learning, Memory, and Cognition, 43, 1793-1820.

Schreuder, R. (1990). Lexical processing of verbs with separable particles. Yearbook of Morphology, 3, 65-79.

Schreuder, R., \& Baayen, R. H. (1995). Modeling morphological processing. Morphological Aspects of Language Processing, 2, 257-294.

Schreuder, R., Burani, C., \& Baayen, R. H. (2003). Parsing and semantic opacity. Reading complex words (pp. 159-189). Springer.

Seidenberg, M. S., \& Gonnerman, L. M. (2000). Explaining derivational morphology as the convergence of codes. Trends in Cognitive Sciences, 4, 353-361.

Singson, M., Mahony, D., \& Mann, V. (2000). The relation between reading ability and morphological skills: Evidence from derivational suffixes. Reading and Writing, 12, 219-252.

Smolka, E., Gondan, M., \& Rösler, F. (2015). Take a stand on understanding: Electrophysiological evidence for stem access in German complex verbs. Frontiers in Human Neuroscience Article 62.

Smolka, E., Khader, P. H., Wiese, R., Zwitserlood, P., \& Rösler, F. (2013). Electrophysiological evidence for the continuous processing of linguistic categories of regular and irregular verb inflection in German. Journal of Cognitive Neuroscience, 25, 
1284-1304.

Smolka, E., Komlosi, S., \& Rösler, F. (2009). When semantics means less than morphology: The processing of German prefixed verbs. Language and Cognitive Processes, 24, 337-375.

Smolka, E., Libben, G., \& Dressler, W. U. (2019). When morphological structure overrides meaning: evidence from German prefix and particle verbs. Language, Cognition and Neuroscience, 34, 599-614.

Smolka, E., Preller, K. H., \& Eulitz, C. (2014). 'Verstehen' ('understand') primes 'stehen' ('stand'): Morphological structure overrides semantic compositionality in the lexical representation of German complex verbs. Journal of Memory and Language, 72, 16-36.

Stanners, R. F., Neiser, J. J., Hernon, W. P., \& Hall, R. (1979). Memory representation for morphologically related words. Journal of Memory and Language, 18, 399.

Stockall, L., \& Marantz, A. (2006). A single route, full decomposition model of morphological complexity: MEG evidence. The Mental Lexicon, 1, 85-123.

Taft, M. (1979). Recognition of affixed words and the word frequency effect. Memory \& Cognition, 7, 263-272.

Taft, M. (2004). Morphological decomposition and the reverse base frequency effect. Quarterly Journal of Experimental Psychology Section A, 57, 745-765.

Taft, M., \& Forster, K. I. (1975). Lexical storage and retrieval of prefixed words. Journal of
Verbal Learning and Verbal Behavior, 14, 638-647.

Ussishkin, A., Dawson, C. R., Wedel, A., \& Schluter, K. (2015). Auditory masked priming in Maltese spoken word recognition. Language, Cognition and Neuroscience, 30, 1096-1115.

Voga, M., \& Giraudo, H. (2009). Pseudo-family size influences the processing of French inflections: Evidence in favor of a supralexical account. Selected proceedings of the 6 th Décembrettes: Morphology in Bordeaux (pp. 148-155).

Whiting, C., Shtyrov, Y., \& Marslen-Wilson, W. (2014). Real-time functional architecture of visual word recognition. Journal of Cognitive Neuroscience, 27, 246-265.

Wilder, R. J., Goodwin Davies, A., \& Embick, D. (2019). Differences between morphological and repetition priming in auditory lexical decision: Implications for decompositional models. Cortex, 116, 122-142. https://doi.org/10.1016/j.cortex.2018.10. 007 .

Wurm, L. H. (2000). Auditory processing of polymorphemic pseudowords. Journal of Memory and Language, 42, 255-271.

Zwitserlood, P., Bolwiender, A., \& Drews, E. (2005). Priming morphologically complex verbs by sentence contexts: Effects of semantic transparency and ambiguity. Language and Cognitive Processes, 20, 395-415. 